Document downloaded from:

http://hdl.handle.net/10251/65116

This paper must be cited as:

Arias Carrascal, KS.; Climent Olmedo, MJ.; Corma Canós, A.; Iborra Chornet, S. (2015). Synthesis of high quality alkyl naphthenic kerosene by reacting an oil refinery with a biomass refinery stream. Energy and Environmental Science. 8(1):317-331. doi:10.1039/c4ee03194f.

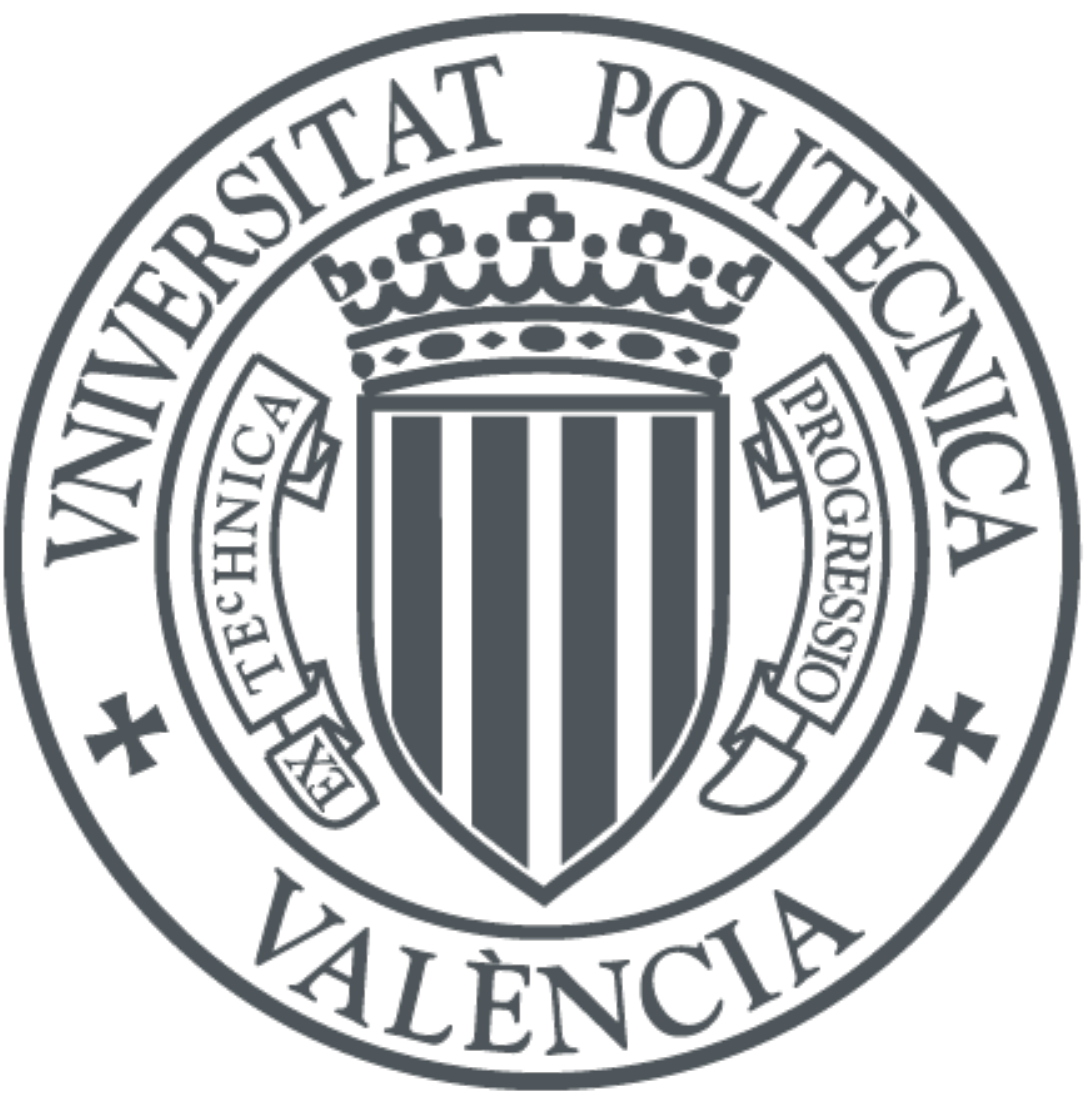

The final publication is available at

http://dx.doi.org/10.1039/c4ee03194f

Copyright Royal Society of Chemistry

Additional Information 


\title{
Synthesis of high quality alkyl naphthenic kerosene by reacting oil refinery with
}

\section{biomass refinery stream}

\author{
Karen S. Arias, Maria J. Climent, Avelino Corma, ${ }^{*}$ Sara Iborra \\ Instituto de Tecnología Química (UPV-CSIC) \\ Universitat Politécnica de València \\ Avda dels Tarongers s/n, 46022, Valencia (Spain) \\ Fax: (+34) 963877809 \\ E-mail: acorma@itq.upv.es
}

\section{Abstract}

Alkylation of aromatics with HMF is a new route for the synthesis of biofuels. Alkylation of toluene with HMF has been studied in the presence of large pore (HBeta, USY and Mordenite), delaminated zeolites as well as on mesoporous aluminosilicates. In all cases a mixture of monoalkylated of 5-(o-, m- and p-methyl)benzylfuran-2carbaldehyde and OBMF coming from self etherification of HMF were obtained. Large pore 3D (USY) and especially 2D (ITQ-2) zeolites are active and selective catalysts for this transformation. The alkylation reaction was extended successfully to other substituted benzenes as well as to a heavy reformate mixture as a source aromatic compounds, achieving $91 \%$ yield of alkylated products with $93 \%$ selectivity. Further hydrodeoxygenation of alkylated compounds in a fixed bed continuous reactor was performed using $\mathrm{Pt} / \mathrm{C}$ and $\mathrm{Pt} / \mathrm{TiO}_{2}$ as catalysts allowing to obtain a hydrocarbon mixture containing alkylcyclohexane compounds that can be used as high quality kerosene.

Keywords: biofuels, 5-hydroxymethylfurfural, Friedel-Craft alkylation, ITQ-2 zeolite, USY zeolite 


\section{Introduction}

In the last decade, policies related with sustainability and reduction of carbon dioxide emissions, have stimulated research to develop efficient processes for the transformation of renewable biomass into fuels and chemicals, ${ }^{1,2}$ being lignocellulosic biomass the most appropriated feedstocks since does not compete with food supplies. The production of fuels and chemicals from this renewable resource involves different direct routes such as direct pyrolysis or catalytic pyrolysis of the lignocelluloses, ${ }^{3}$ hydrothermal treatment under pressure and temperature, ${ }^{4}$ and gasification to produce synthesis gas.

There is another way to process the biomass that requires to separate their components into lignin, cellulose and hemicellulose. ${ }^{5}$ This route opens the possibility for hydrolysis of cellulosic and hemicellulosic components to produce C5 and C6 sugars, which are converted into fuels and chemicals by either fermentations or chemical reactions. An interesting approach to convert biomass into fuels and chemicals is through the transformation of the so called platform molecules. ${ }^{6}$ Among them, 5-hydroxymethylfurfural (HMF) coming from dehydration of hexoses (glucose and fructose) appears as one of the most promising platform molecule due to its chemical versatility, which allows to convert HMF into a wide variety of high value chemicals and alternative biofuels. ${ }^{1,2,7}$

HMF is produced by acid dehydration of $\mathrm{C} 6$ carbohydrates such as fructose, glucose or polymeric carbohydrates such as starch, inulin, cellulose and raw biomass, being Dfructose the feed of choice. While aqueous processes appears to be the most 
convenient from an environmental point of view, they are not efficient since under acidic aqueous conditions, polymerization and hydrolysis of HMF to levulinic and formic acid occur giving low yield of $\mathrm{HMF}^{8}{ }^{8}$ In order to overcome HMF degradation and to optimize the HMF yield, a variety of homogeneous and heterogeneous acid catalysts, solvents and biphasic reaction system for the production of HMF have been used with different success, and they have been extensively reviewed recently. ${ }^{9}$

In the non-aqueous systems, the hydrolysis of HMF can be suppressed, however the cross-polymerization reactions also occurs. The use of high boiling point polar solvents such as DMSO and DMF, habitually allows to obtain high yields of $\mathrm{HMF}(90 \%),{ }^{10}$ however the extraction of HMF from these solvents is rather complicated. An interesting approach for the production of HMF, which could be applied at large scale, is the use of solvent/aqueous biphasic systems since the extraction of HMF from the aqueous phase avoids its degradation. ${ }^{11}$ However, the key issue of these biphasic systems is the high extraction efficiency of the solvent and its recyclability.

Despite the attractive functionality of $\mathrm{HMF}$ and the great efforts for finding an optimized method of HMF production, HMF was not industrially manufactured until very recently. ${ }^{12}$ However, a few months ago, recently AVA Biochem has announced "the first commercial-scale production of HMF from biomass" at its Biochem-1 facility. ${ }^{13}$ The process, which is based on a hydrothermal carbonization of lignocelluloses feedstock (HTC), ${ }^{14}$ will produce, in the first phase, up to 20 tonnes of HMF per year in various levels of purity (up to 99\%).

Several platform molecules can be transformed into liquid hydrocarbon fuels by catalytic routes involving deoxygenation combined with C-C coupling reactions. ${ }^{2,15}$ For instance Levulinic acid (LA) can be converted into liquid hydrocarbon fuels via gamma 
valerolactone through two routes. One of them involves the ring opening of GVL into pentenoic acid isomers which can be subsequently decarboxylated over a $\mathrm{SiO}_{2} / \mathrm{Al}_{2} \mathrm{O}_{3}$ catalyst producing an equimolar mixture of butenes and $\mathrm{CO}_{2}$. The oligomerization of butenes over an acidic catalyst produces alkenes which can be used as jet fuel upon hydrogenation. ${ }^{16}$ However the oligomerization products of molecular size in the range of $\mathrm{C} 8$ are not suitable for diesel formulation and therefore the diesel yield is reduced to $20 \%$. Another route to produce liquid alkanes from levulinic acid is via production of pentanoic acid through ring-opening/hydrogenation of GVL on a bifuctional (acidmetal) catalyst. Ketonization of two molecules of pentanoic acid can be performed over a variety of heterogeneous catalyst such as zirconium oxide, zirconium-cerium mixed oxide, cerium oxide, alumina, silica or $\mathrm{MgO}^{17,18,19}$ yielding 5-nonanone along with $\mathrm{CO}_{2}$ and water. 5-nonanone can be upgraded to liquid alkanes, through its hydrogenation/dehydration to n-nonane using bifunctional catalysts such as $\mathrm{Pt} / \mathrm{C}$ or $\mathrm{Pt} / \mathrm{TiO}_{2}{ }^{17}$ and $\mathrm{Pt} / \mathrm{Nb}_{2} \mathrm{O}_{5}$ or $\mathrm{Pt} / \mathrm{Al}_{2} \mathrm{O}_{3}{ }^{18}$

Kunkes et al. ${ }^{20}$ have developed a process to produce higher alkanes starting from polyiols, such us sorbitol, which consist of a two-step cascade process that combines oxygen removal and $\mathrm{C}-\mathrm{C}$ coupling reactions. Polyols are firstly deoxygenated over a Pt$\mathrm{Re} / \mathrm{C}$ catalyst giving a mixture of organic compounds in the C4-C6 range which contains acids, alcohols, ketones and heterocycles. In a subsequent step, this mixture is converted into higher hydrocarbons through different C-C coupling reactions such as aldol or ketonization processes. However, a drawback of the process is the high cost of the catalyst.

Starting from different furan derived platform molecules such as furfural, 5hydroxymethylfurfural and 2-methylfuran different strategies involving C-C bond 
formation reactions have been developed in order to produce liquid biofuels. For instance, Corma et al. $^{21,22,23}$ have selected the hydroxyalkylation/alkylation of 2methylfuran just with itselfs or with other aldehydes or ketones in the presence of an acid catalyst (such as sulphuric acid or solid acid catalysts). A C-C bond formation occurs to obtain intermediate oxygenated molecules, which are converted subsequently into alkanes with excellent diesel properties ${ }^{23}$ through a hydrodeoxygenation step. Dumesic et al. ${ }^{24,25}$ have proposed as carbon-carbon forming reaction, the aldol condensation of furfurals (furfural and 5-hydroxymethyl furfural) with ketones (such as acetone) to produce the mono and bis-aldol condensate products, which by subsequent hydrodeoxygenation generate linear alkanes. However, this cross-aldol condensation also involves the self condensation of the ketone leading to lower selectivity to de desired compound. To overcome this problem an alternative is to perform firstly the hydrogenation of the furan ring of HMF and furfural to give 5hydroxymethyltetrahydrofurfural and tetrahydrofurfural which after self condensation and hydrogenation/dehydration process yield C12 and C10 alkanes respectively. ${ }^{26}$

Another strategy to obtain diesel fuel precursors from furan derived platform molecules, such as HMF, is the Friedel-Crafts alkylation of arenes (derived from oil or from lignin) with HMF. This reaction has been mainly performed using $\mathrm{FeCl}_{3}$ as Lewis acid catalyst. For instance, Lovel et al. ${ }^{27}$ performed the alkylation of o-xylene with $\mathrm{HMF}$ in the presence of $\mathrm{FeCl}_{3}(10 \mathrm{~mol} \%)$ at $80{ }^{\circ} \mathrm{C}$ yielding $37 \%$ of a mixture of 4 - and 3 substituted-xylenes (62:38) after $24 \mathrm{~h}$ reaction time. More recently Zhou et al. ${ }^{28}$ performed the Friedel-Crafts alkylation between HMF and mesitylene in nitromethane as a solvent. When using $\mathrm{FeCl}_{3}(10 \mathrm{~mol} \%)$ as catalyst, $94 \%$ yield of mesitylmethylfurfural was obtained after $1 \mathrm{~h}$, while with $\mathrm{p}$-toluenesulfonic acid (10 
mol\%) only $76 \%$ yield was achieved after $2 \mathrm{~h}$. Additionally the authors reported that formic acid can act as solvent and catalyst for the one pot process involving the dehydration of fructose or glucose to HMF that, by alkylation of mesitylene gives mesitylmethylfurfural with reasonable yields (20-70\%). While the above procedures are interesting, they present some drawbacks for the synthesis of 5-benzyl HMF derivatives, i.e., use of volatile and toxic solvents such as nitrometane and the presence of homogeneous Lewis or Bronsted catalysts which require a neutralization step, avoiding the recovery and reuse of the catalyst. Therefore, the development of new catalytic processes able to produce alkylated HMF derivatives by more sustainable methods with heterogeneous acid catalysts and avoid the use of solvents is of much interest. Following this, Onorato el al. $^{29}$ have recently used poly(3,4ethylenedioxythiophene) (PEDOT ${ }^{+}$) salts as acid catalysts to perform the dehydration of different ketohexoses to HMF. The authors found that when the reaction is performed using fructose at reflux of toluene a mixture of ortho and para 5-(methyl)benzylfuran2-carbaldehyde in $84 \%$ yield was obtained and similar results were obtained when reacting HMF with toluene. However, in both processes high substrate/catalyst (1:1) molar ratios as well as long reaction times $(20 \mathrm{~h})$ were required.

While the alkylation of aromatic compounds by alkyl and benzyl halides, alcohols and

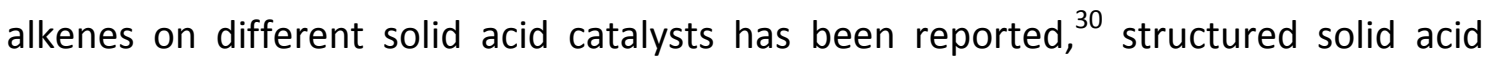
catalysts with good accessibility for larger molecules can present an opportunity for this type of reactions. Therefore we present here the conversion of HMF into 5-benzyl HMF derivatives on large pore and delaminated zeolites as well as on mesoporous aluminosilicates. There is not doubt that if one could design a solid catalyst that would avoid competitive reactions such polyalkylations and self etherification of HMF, while 
maximizing alkylation of aromatics with HMF, new opportunities will be opened for the synthesis of biofuels and chemicals. It has to be remarked that while the methods reported above produce linear or branched alkanes, the production and hydrodeoxygenation of 5-benzyl HMF derivatives, besides to be a selective and environmental friendly process, produces alkyl cycloalkanes which have high densities and volumetric heating values due to robust ring strain. This variety of compounds distributed over the diesel and jet range can be added to the conventional fuels to increase the density or volumetric heating of the fuel.

\section{Results and discussion}

\subsection{Alkylation of Toluene with HMF in the presence of acid catalysts}

Two different routes allow to obtain 5-benzyl HMF derivatives starting from HMF: Friedel-Crafts alkylation of aromatic compounds with 5-chloromethyl-2-furfural in the presence of an excess of Lewis acid catalysts (see Scheme 1a), and by the direct reaction of HMF in the presence of Bronsted acids (see Scheme 1b). When homogeneous Lewis or Bronsted acids are used in a conventional alkylation reaction a large amounts of residues such as salts or polyalkylated compounds are generated. Moreover using halides such as 5-chloromethyl-2-furfural, an additional halogenation reaction is required. This step could be avoided if solid acid catalysts could carry out the direct alkylation of aromatic compounds and HMF with high conversion and selectivities. Among solid acids, zeolites may offer interesting opportunities for this type of reactions since they have been applied successfully to a large number of alkylation processes. $^{31}$ 
Considering the size of the reaction products, suitable zeolites for alkylations of aromatics with HMF will require a pore-structure system that allows faster diffusion of products out of the pores to avoid multiple alkylations and catalyst deactivation. Then, two dimensional (2D) or layered zeolites, as well as structured mesoporous materials can be an adequate choice. On the other hand, since different isomers, i.e. meta, ortho and para can be obtained when alkylating alkylaromatics with HMF, pore dimensions and topology should have an impact on product distribution. Based on the above premises, we have selected as starting reference three protonic large pore zeolites with different pore topologies and close pore diameters $(\sim 0.7 \mathrm{~nm})$ : HMordenite, with a system of unidimensional twelve ring pores (12R); HBeta zeolite with a system of tridirectional $12 \mathrm{R}$ pore without cavities and finally a tridirectional $12 \mathrm{R}$ pore zeolite that contains cavities (Faujasite Y Zeolite). The main characteristics of the zeolites used are given in experimental section.

For starting, toluene was used first as a model aromatic molecule for studying the alkylation reaction with HMF. Then, when, the reaction between HMF and toluene was carried with HBeta zeolite (Si/Al ratio of 12 ) at $115{ }^{\circ} \mathrm{C}$ the corresponding monoalkylated products, a mixture of 5-(o-, $\mathrm{m}$ - and p-methyl)benzylfuran-2carbaldehyde was obtained with $54 \%$ yield after 8 h (see Figure 1 and Table 1). Moreover, 5,5'-(oxy-bis(methylene))bis-2-furfural (OBMF) coming from the self etherification of HMF (Scheme 2) was also obtained in 15\% yield, while polyalkylated, oligomers, and compounds coming from the hydroxyalkylation of the aromatic ring were not detected in the reaction media. No products were detected when the reaction was carried out in absence of catalyst. 
The formation of products could be explained by considering that the hydroxylmethyl group of HMF reacts on acid sites to form the methylfurfuryl cation, which can react with the aromatic ring giving the 5-benzylfuran-2-carbaldehyde. On the other hand the methylfurfuryl cation can also react with the hydroxyl group of another HMF molecule giving the corresponding ether (OBMF) (Scheme 2).

The yields of 5-alkylated-HMF and the OBMF products were plotted versus reaction time, and both appear as primary products (Figure 1). As can be seen there, the initial reaction rate for the formation of 5 -alkylated products is faster than formation of OBMF, indicating that under our reaction conditions the alkylation reaction is preferred with respect to the self etherification of HMF. The result is not surprising considering that we work under a large excess of the aromatic compound. Despite this, the kinetic curves in Figure 1 show the reaction stops before complete conversion indicating a deactivation of the catalysts. That can be attributed to the formation of polyalkylated or, in general, to the formation of bulky products which can remain strongly adsorbed inside of the microspores of the Beta zeolite and which can hardly diffuse out, blocking active sites or even pores. To check this hypothesis we have determined the amount of organic products remaining adsorbed on the zeolite after reaction by TG-MS, and the "coked" sample was subjected to Soxhlet extraction with dichloromethane. By doing this we obtained $4.4 \mathrm{mg}$ of organic (composed by toluene, OBMF and alkylated compounds) on the solid that corresponds to $28 \mathrm{wt} \%$ with respect to the catalyst weight. Moreover, nitrogen adsorption was performed on the used catalyst after extraction with dichloromethane, and an important decrease of the pore volume of the catalyst after the reaction was observed going from $0.18 \mathrm{ccg}^{-1}$ for the fresh sample to $0.08 \mathrm{ccg}^{-1}$ for the used zeolite. The micropore volume decrease 
confirms that there is an important reduction of the internal pore volume by pore blocking with reaction products.

For comparison purposes, the alkylation of HMF was performed in the presence of $p$ toluenesulfonic acid (PTSA) as catalyst and the results are showed in Table 1 and Figure 2. As can be seen there, PTSA promotes the self etherification of HMF at much higher rate than alkylation, achieving a maximum concentration of OBMF that then decreases with time. In this case, the strong acidity of the homogeneous catalyst and the absence of diffusional limitations favour the alkylation of toluene by the OBMF achieving a final selectivity to the alkylated compounds of $95 \%$ after $24 \mathrm{~h}$ reaction time.

With respect to selectivity at the different regioisomers (see Figure 3 ), the ratio of para/ortho isomers observed for the homogeneous catalyst, was approximately 1.2, which is similar to the value reported for the alkylation of toluene with benzyl alcohol using Nafion-H as catalyst. ${ }^{32}$ However, Beta zeolite was much more selective to the para-isomer (less sterically impeded) than p-toluenesulfonic or Nafion, with a para to ortho ratio of 3.0, with little selectivity to the electronically disfavored meta-isomer. It should be noticed that the para to ortho ratio decreases with reaction time (not showed), probably indicating a larger contribution of the external surface of the zeolite when the pores of the catalyst become blocked.

At this point we thought that perhaps HMordenite could yield a higher para/ortho ratio, although we were since the first moment concern about the potential faster deactivation of the unidimensional zeolite by pore blocking. Indeed, a much faster deactivation was observed in the case of the HMordenite with respect to HBeta, together with a much higher selectivity to OBMF (see Figure 4 and Table 1). 
Meanwhile, no benefit on the para to ortho ratio was obtained. After these results the HMordenite was already rejected as a potential catalyst for the alkylation of aromatics with HMF.

The following step in the study was to use a tridimensional zeolite with larger pores than HBeta, and ultra stable $\mathrm{Y}$ zeolites USY samples were selected as alkylation catalyst. This type of zeolites has shown to be active and stable for the alkylation of aromatic molecules with alcohols. ${ }^{33}$ Indeed, we have found that when toluene and HMF were reacted in the presence of a USY zeolite (USY-720) with a unit cell size of $24.32 \AA$, equivalent to a framework Si/Al ratio of 19 , the results in Figure 5 show a high selectivity to the desired alkylated product with low selectivity to the undesired OBMF ether.

Interestingly, $100 \%$ conversion is achieved very fast, suggesting not only a high activity but also probably a slower rate of deactivation. In an analogous way, as was done previously with HBeta, the amount of organic remaining and the micropore volume of USY zeolite after reaction and Soxhlet extraction were measured. The results presented in Table 2 show that the amount of remaining organic and the percentage of the micropore volume lost follows the order Beta> USY> Mordenite.

The organic remaining on the USY-720 zeolite was burned off by calcination at $450{ }^{\circ} \mathrm{C}$ during $3 \mathrm{~h}$, and the catalyst was reused again. The kinetic curves in Figure 6a-b compare the results with fresh Beta and USY-720 and the corresponding regenerated catalysts. It can be seen there that the activity can be perfectly restored by calcination of the catalysts in air. However, when the para to ortho ratio is considered (see Figure $3)$ it is possible to see that owing to the large cavities $(\sim 1.2 \mathrm{~nm})$ present in the USY 
zeolite that ratio is practically the same than the one obtained with PTSA in where no geometrical restrictions from pore exist. In other words, USY-720 is a very active and selective zeolite that allows alkylation to occur freely within the cavities, while products can diffuse out.

Since pore dimensions and topology of $Y$ zeolite seems to be convenient, we have explored the implications of the framework composition/acidity (framework Si/Al ratio), as well as the influence of the mesoporosity of different ultrastable $Y$ zeolite (USY) on catalyst activity, selectivity and catalyst decay.

In order to check the influence of the framework Si/AI (FAL), four commercial USY samples with different Al content: USY-500, USY-712, USY-720 and USY-760 and similar crystallite size (see Table S1 in SI) were selected. Measurements of acidity and physicchemical characteristics are presented in Tables 3 y 4.

The alkylation of toluene with HMF was performed with these samples and the initial rate of alkylation versus Si/Al framework (FAL) is displayed in Figure 7. As can be seen, maximum activity was found at framework Si/Al ratio between 18.6 and 63, indicating that the amount of framework Al plays an important role on the catalytic activity. In fact, it is known that increasing the Si/Al ratio, the hydrophobic character of a zeolite increases while the number of potential acid sites decreases. In this case it is showed that an optimum in adsorption properties, acidity and catalytic activity exists for a framework Si/Al value of $\sim 19$ that corresponds to 10 Al per unit cell (see Tables 3-5).

Additionally, the influence of the framework Si/Al ratio on deactivation is showed in Figure 8. As can be observed, the deactivation rate follows the order USY-500 >USY- 
$712>$ USY-760 >USY-720, showing also in this case the existence of an optimum for catalyst deactivation for the zeolite with $\sim 10$ framework Al per unit cell.

With this value and considering a statistical distribution of $\mathrm{Al}$, the optimum will correspond to a sample in where most of the framework Al will be isolated sites, i.e. Al with no $\mathrm{Al}$ in the next nearest neighbor positions. ${ }^{34}$

\subsubsection{Influence of zeolite mesoporosity}

Since desorption and diffusion of products is an important parameter when the reaction is performed with zeolites, the influence of the mesoporosity in the USY zeolite has been studied by starting with a commercial USY sample (USY-300). Then, USY-300 was subjected to a sequence of post-synthetic modifications which included dealuminization using $\mathrm{H}_{4}$ EDA, followed by desilication in $\mathrm{NaOH}$, and finally acid washing in $\mathrm{Na}_{2} \mathrm{H}_{2}$ EDTA. The physico-chemical characteristics of the resulting material (USY-MY) are showed in Table 6. As can be observed there crystallinity and micropore volume are decreased during the generation of mesopores in good agreement with previous results. ${ }^{35}$ However, in spite of the decrease in crystallinity, the USY-MY sample is not significantly dealuminated according to the unit cell size values determined by XRD and the ${ }^{27} \mathrm{Al}$ MAS-NMR spectra (not showed) which exhibits a single peak centered at a chemical shift of around $60 \mathrm{ppm}$, and assigned to tetrahedrally coordinated $\mathrm{Al}^{36}$. Additionally, the Bronsted acidity of USY-MY sample is increased possibly as a consequence of the decrease of the sodium content during the post-synthetic treatment.

The alkylation of toluene with HMF was performed using USY-300 and USY-MY samples. Figure 9, shows that the activity of USY-300 zeolite is very low which can be 
attributed to the high sodium content. However in contrast, the mesoporous USY-MY sample showed higher catalytic activity than the precursor sample (USY-300) (Figure 10), achieving around $40 \%$ of HMF conversion after $8 \mathrm{~h}$. When the activity of USY-MY sample is compared with those exhibited by a sample (USY-500) with similar unit cell size value, i.e. similar framework aluminum content but higher acidity it is possible to see that the later exhibits considerable lower activity (see Table 3), achieving only $15 \%$ conversion of HMF after $8 \mathrm{~h}$ reaction time. These results clearly indicate that the generation of intracrystalline mesopores in the USY zeolite has a very positive effect on the catalytic activity for the alkylation of toluene with HMF.

Additionally, we reduced the Na content of the USY-MY by a conventional ammonium exchange procedure followed by calcination in order to study the influence of increasing acidity in the mesoporous sample. The ammonium exchanged sample (USYHMY) obtained, had a $\mathrm{Na}_{2} \mathrm{O}$ content below $0.1 \%$. As can be seen in Table 6, mesoporosity of this material is preserved, however a loss of micropore volume and framework aluminum, with a considerable decrease in acidity is evidenced. Unfortunately, these changes affect significantly to the catalytic activity and in fact, only $10 \%$ of conversion of HMF was achieved after $8 \mathrm{~h}$ reaction time (see Figure 11 ).

Since diffusional effects are important for the alkylation of toluene with HMF, we have also considered the possibility of using a two dimensional layered zeolite, in where most of the surface can be considered as external surface (ITQ-2). The catalytic results obtained with this type of material will be described below. 


\subsubsection{D Layered Zeolites as Alkylation catalyst for toluene with HMF}

The MWW zeolite topology, ${ }^{37}$ is an excellent catalyst together with Beta zeolite to perform the alkylation of benzene with olefins. ${ }^{38}$ It has been reported that the alkylation mainly occurs on the external surface of MWW and because of that a new type of 2D layered zeolite with well structured and very large external surface area were developed by delamination of a laminar precursors of different zeolites. ${ }^{39,40,41}$

In the case of the laminar precursor of MWW, the 2D layered zeolite ITQ-2 was prepared in where the $12 \mathrm{R}$ hemicavities similar to cups are exposed to the exterior ready to adsorb-react-desorb without requiring diffusion through micropores ${ }^{42}$ (see Figure 12 and Figure 1 Supporting information). Since this material with external surface areas larger than $600 \mathrm{~m}^{2} / \mathrm{g}$ was shown to be more active for alkylation of biphenyl with propene than the corresponding 3D MWW zeolite, ${ }^{43}$ we have studied here, the catalytic behavior of ITQ-2 for alkylation of toluene with HMF. Results in Figure 12 and Table 1 show that this is an active zeolite with a very low initial rate for OBMF formation. Moreover, it is observed that the OBMF formed also reacts with toluene giving the alkylated compounds with, a final selectivity of $99 \%$ at $99 \%$ of HMF conversion (see Figure 12). No deactivation can be inferred from the kinetic curves. However since batch reactors are not the best to discuss catalyst decay from the kinetic curves the used ITQ-2 was tested again after reaction and Soxhlet extraction. Results in Figures 13 and 14 indicate that ITQ-2, as it occurs with USY-720, strongly deactivate during the reaction, reaching only a $10 \%$ of the initial reaction rate. In any case, the initial activity of ITQ-2 and USY-720, catalysts can be restored after calcination at $450{ }^{\circ} \mathrm{C}$ for $3 \mathrm{~h}$. 
Interestingly, while the alkylation isomer distribution for USY-720 was similar to that of PTSA, ITQ-2 clearly gives the highest para/ortho ratio among the zeolites studied (see Figure 3), indicating the key role played by the external "cup" like hemicavities (see Figure 1 Supporting Information) during the catalytic reaction. It appears then, that the excellent catalytic behavior of ITQ-2 is due to the presence of zeolitic type of acidity together with a well structured very high external surface area formed by cup like hemicavities. This cups are not connected with the microporous channel system, and allow reaction and desorption of the products. Notice that the ITQ-2 retains the initial activity and selectivity after four cycles reaction-regeneration (see Figure 15).

Since acid strength, diffusion and desorption are key catalyst variables, we decided to study finally the catalytic behavior of structured mesoporous materials, and more specifically MCM-41 material. The acidity shown by this material is weaker than that of zeolites and closer to the acidities of amorphous silica-alumina. However, the fact that it presents regular pores with approximately $3.5 \mathrm{~nm}$ diameter should allow fast desorption and diffusion of reactants and products. Results in Figure 16 and Table 1 show that while the activity of MCM-41 is reasonable, its selectivity for the formation of the undesired OBMF is the highest. These results are probably due to the lower acidity of the MCM-41 as demonstrated by pyridine adsorption-desorption. With respect to the para/ortho ratio, it is much lower than for ITQ-2.

\subsubsection{Influence of the toluene/HMF ratio on the alkylation reaction}

From an economical point of view it is important to minimize the toluene/HMF ratio while keeping the selectivity to 5-alkylated-HMF at reasonable levels. To study the influence of the ratio toluene to HMF on the selectivity to 5-(o-, $\mathrm{m}$ - and $\mathrm{p}$ - 
methyl)benzylfuran-2-carbaldehyde, the alkylation reaction was performed in the presence of ITQ-2(15) with 47, 94, 189, $472\left(\mathrm{~mol} \mathrm{~mol}^{-1}\right)$ of toluene/HMF molar ratio (which correspond to $2.5,5,10,25 \mathrm{ml}$ of toluene respectively), and the results obtained are given in Table 7. As can be seen there, when the concentration of toluene is reduced, the selectivity to alkylated compounds decreases. In fact, the competitive adsorption of HMF on the acid sites becomes more important, promoting the selfetherification of HMF and giving OBMF in higher yields. It is interesting to notice that working at toluene/HMF molar ratios of 472 ( $25 \mathrm{~mL}$ of toluene) the yield of alkylated compounds is considerably better than the values reported before, working at similar toluene/HMF molar ratios and using PEDOT and salts as heterogeneous catalyst. Moreover, when the amount of ITQ-2 catalyst was increased from 25 wt\% up to 30 and $50 w t \%$ it was possible to achieve excellent yield and selectivity to the alkylated compounds working at lower toluene/HMF molar ratio (see Table 7). Similar results were obtained when the reaction was carried out at $170{ }^{\circ} \mathrm{C}$ using $25 \mathrm{wt} \%$ of catalyst.

\subsubsection{Alkylation of different aromatic hydrocarbons with HMF}

The Friedel-Crafts alkylation was further studied by reacting various substituted benzenes such as $o$-dimethylbenzene, mesitylene and $p$ - methoxybenzene with HMF in the presence of ITQ-2(15) as catalyst. As can be seen in Table 8 good yields of the corresponding 5-benzylfuran-2-carbaldehydes were obtained when activating groups are present in the aromatic ring except in the case of mesitylene. Thus, a fast deactivation of the catalyst was observed achieving a maximum conversion of $55 \%$. In this case it appears that the steric interactions can play an important and negative role. 


\subsubsection{Alkylation of a heavy reformate mixture with HMF}

Regarding the advantages of using ITQ-2 zeolite for converting HMF and aromatic hydrocarbons in alkylated compounds, we have studied the alkylation reaction using a heavy reformate mixture as a source aromatic compounds. Thus, a heavy reformate mixture with the following composition: 1,2,3-trimethylbenzenes (C9) (54 v/v\%), 3ethyl-toluene (C9) (33.4 v/v\%), n-propylbenzene (C9) (6 v/v\%) and o-xylene (C8) (6.6 v/v\%), was reacted with HMF. As can be seen in Figure 17 good activities and selectivities of the alkylated products were obtained. Thus $91 \%$ yield of alkylated products with $93 \%$ selectivity was afforded after $6.5 \mathrm{~h}$ reaction time, being the major alkylated products those corresponding to the more activated hydrocarbon i.e. oxylene and 1,2,3-trimethylbenzene. The different alkylated aromatic hydrocarbon products were identified by comparison with the products obtained performing the alkylation with HMF with pure arenes.

\subsection{Hydrodeoxygenation of 5-(o-, m- and p-methyl)benzylfuran-2-carbaldehyde}

Finally we have studied the possibility to transform 5-(o-, $m$ - and $p$ methyl)benzylfuran-2-carbaldehyde, oxygenated alkylated compound derived from biomass, into a mixture of hydrocarbons and hydrophobic molecules that can be blended with kerosene or diesel. Thus, the hydrodeoxygenation of the alkylated compound was performed in a fixed bed continuous reactor introducing the feed without any solvent after pretreated at $65{ }^{\circ} \mathrm{C}$. We have selected a physical mixture of platinum supported on carbon and on titanium oxide as catalyst to carry out hydrodeoxygenation process. It has been proposed that platinum metal is a good candidate for the hydrodeoxygenation and in the presence of titania the carbonyl 
groups are activate favoring the hydrogenation by platinum. ${ }^{23}$ Thus, a mixture of Pt/C$\mathrm{Pt} / \mathrm{TiO}_{2}$ was prepared as catalyst and the reaction was performed at hydrogen pressure of 40 bar and $350{ }^{\circ} \mathrm{C}$, with a flow rate of $450 \mathrm{ml} / \mathrm{min}$ of hydrogen. After $1.67 \mathrm{~h}$ time on stream, the liquids were separated into an aqueous phase and a transparent light yellow organic phase. GC and GC-MS analysis of the organic phase was used to identify the main products (Table 9). As can be seen the highest selectivity was to saturated hydrocarbons (77.49\%), followed by mono-aromatic hydrocarbons (16.82\%), diaromatic and triaromatic hydrocarbons $(<5 \%)$ and polar compounds $(0.21 \%)$. Thus, the main product obtained, 1-hexyl-4-methylcyclohexane is the C13 alkanes generate by hydrogenation of the unsaturated double $\mathrm{C}-\mathrm{C}$ bond, ring opening and complete hydrogenolysis of all carbon-oxygen bonds as can be seen in Scheme 3 . The second most abundant, a C12 alkane molecule (see Scheme 3), results from a decarbonylation reaction. A very low amount $(2.61 \%)$ of hydrocarbon products with $>\mathrm{C} 13$ atoms were also detected indicating that carbon-carbon bond formation occurred, though at little extension, under our reaction conditions.

The gas phase products ( $4.1 \%$ yield), included $C_{1}$ to $C_{6}$ alkanes, traces of propylene, $C O$ and $\mathrm{CO}_{2}$.

The simulated distillation of the organic phase (see Figure 18) showed that most of the products are in the kerosene range $\left(200-300{ }^{\circ} \mathrm{C}\right)$. One can expect that a kerosene, like the one produced here containing a large amount of alkylcyclohexane products, with high energy density and low smoke point, should be a high quality kerosene.

With respect to the gasoline obtained, which corresponds to $19 \mathrm{wt} \%$, it has an excellent Research (RON) and Octane number (MON) of 93 and 88 respectively according to the 
PIONA analysis. ${ }^{44}$ We have performed a detailed analysis of the products boiling in the gasoline range (up to $200^{\circ} \mathrm{C}$ ) (Figure S2), and the main products are given in Scheme 4 . We can see there that the most of the products up to $\mathrm{C} 10\left(200{ }^{\circ} \mathrm{C}\right.$ B.P. $)$ are alkyl cycloalkanes coming from cracking-hydrogenation of the products formed by alkylation of toluene with HMF. The cracking will probably occur on some acid sites of the catalysts support (titania and carbon) thought the occurrence of some additional hydrogenolysis on the metal can not be neglected. Notice that toluene is also formed supporting the idea that some cracking is taking place during the hydrogenation (Scheme 4)

\section{Conclusions}

We have showed that is possible to alkylate aromatics with HMF with very good activity and selectivities using large pore 3D and especially 2D zeolites. The 2D delaminated zeolite ITQ-2 is an excellent shape selective catalyst for alkylation of aromatics wit HMF that can be subjected to multiple reaction-regenerations cycles. This catalyst can be used to alkylate heavy reformate fractions with HMF with very good yields to alkylated products, which after hydrodeoxygenation yield and excellent kerosene. The process showed here allows reacting feeds reach in aromatics coming from refineries or produced from lignin, with HMF to yield high quality kerosene.

\section{Experimental Part}

\subsection{Materials and catalyst}


5-Hydroxymethyl-2-furfural (99\%), p-methoxybenzene, toluene, o-dimethylbenzene, mesitylene, nonane, p-toluenesulfonic acid were acquired from Sigma-Aldrich and all the solvents were used without dried before its use.

HBeta (CP811) (Si/Al=12.5), Mordenite (CBV 20A) (Si/Al=10), USY (CBV 500, CBV 712, CBV 720, CBV 760) (Si/Al=2.7, 5.7, 12.2, 27 respectively) zeolites were purchased from PQ Zeolites B. V. and before use were calcined at $580{ }^{\circ} \mathrm{C}$ for $3 \mathrm{~h}$. The following catalysts were prepared according to the literature: $\mathrm{MCM}-41(\mathrm{Si} / \mathrm{Al}=15) \cdot{ }^{45} 2 \mathrm{D}$ layered ITQ-2 $(\mathrm{Si} / \mathrm{Al}=15)$ catalyst was prepared by expansion and subsequent exfoliation of the corresponding laminar precursors of the MWW structure by following the reference. ${ }^{39}$ IR spectra were obtained on a Nicolet 750 FTIR spectrophotometer, using wafers of 10 $\mathrm{mg} \mathrm{cm}{ }^{2}$ treated under vacuum $\left(10^{4}\right.$ to $\left.10^{5} \mathrm{~Pa}\right)$ at $400{ }^{\circ} \mathrm{C}$ during overnight. After equilibration, the samples were degassed for $1 \mathrm{~h}$ at increasing temperatures $(150,250$, and $350{ }^{\circ} \mathrm{C}$ ). After each desorption step, the spectrum was recorded at room temperature and the background subtracted.

Surface area measurements were obtained with a Micrometrics ASAP 2000 apparatus following the BET procedure by means of nitrogen and argon adsorption at 77 and 85 $\mathrm{K}$, respectively. Thermogravimetric analyses (TGA) was performed with a Netzsch STA $409 \mathrm{EP}$ thermal analyzer with about $20 \mathrm{mg}$ of sample and a heating rate of $10{ }^{\circ} \mathrm{C} \mathrm{min}{ }^{-1}$ in air flow. Physicochemical characteristics of the different samples studied are presented in Table 1.

The metal catalysts $\left(\mathrm{Pt} / \mathrm{C}\right.$ and $\mathrm{Pt} / \mathrm{TiO}_{2}$ ) were prepared by the incipient wetness impregnation procedure. The desired amount of metal precursor (hexachloroplatinic acid) was dissolved in the water amount determined before. The carbon and metal 
oxide support were impregnated as pellets (particle size of 0.425 to $0.850 \mathrm{~mm}$ ) and dried at $100{ }^{\circ} \mathrm{C}$ overnight.

\subsection{Alkylation reactions}

Synthesis of 5-(o, m and p-substituted)benzylfuran-2-carbaldehyde

A mixture of HMF $(0.5 \mathrm{mmol})$, the corresponding substituted benzene $(25 \mathrm{ml})$ and solid acid catalyst (15.75 mg) (previously activated at $200{ }^{\circ} \mathrm{C}$ under vacuum(1 Torr) for $2 \mathrm{~h}$ ) was heated at $115^{\circ} \mathrm{C}$ while stirring under a nitrogen atmosphere using a silicon bath and condenser. The reaction was followed by taking samples at regular periods of time using nonane as external standard and analyzed by gas chromatography using a flame ionization detector and a capillary column (HP5, $30 \mathrm{~m} \times 0.25 \mu \mathrm{m} \times 0.25 \mathrm{~mm}$ ). After reaction the catalyst was filtered off and evaporated at reduced pressure. The isomeric composition of the 5-(o, $\mathrm{m}$ and p-substituted)benzylfuran-2-carbaldehyde resulting from benzene derivatives were identified by ${ }^{1} \mathrm{H},{ }^{13} \mathrm{C}$ NMR spectroscopy and CG-MS chromatography. ${ }^{1} \mathrm{H}-\mathrm{NMR}$ and ${ }^{13} \mathrm{C}-\mathrm{NMR}$ spectra were recorded by using a Bruker Avance $300\left({ }^{1} \mathrm{H} 300 \mathrm{MHz},{ }^{13} \mathrm{C} 75 \mathrm{MHz}\right)$ in $\mathrm{CDCl}_{3}$. The chemical shifts are given in ppm and the $J$ values are given in $\mathrm{Hz}$. Abbreviations were defined as follows: $\mathrm{s}=$ singlet, $\mathrm{d}=$ doublet, $\mathrm{t}=$ triplet, $\mathrm{m}=$ multiplet.

\section{Catalyst reuse}

For catalyst reuse, the catalyst was collected after reaction by vacuum filtration, and it was calcined at $450{ }^{\circ} \mathrm{C}$ for $3 \mathrm{~h}$ under air flow and used in subsequent cycles.

\section{Spectroscopic data of alkylated compounds:}


5-(o- $\boldsymbol{m}$ and $\boldsymbol{p}$-Methyl)benzylfuran-2-carbaldehyde: ${ }^{1} \mathrm{H} \mathrm{NMR}\left(\mathrm{CDCl}_{3}\right): \delta 9.53(\mathrm{~s}, 2 \mathrm{H})$, 7.11-7.32 (m, 8H), $6.16(\mathrm{~d}, J=2.8 \mathrm{~Hz}, 1 \mathrm{H}), 6.12(\mathrm{~d}, J=2.5 \mathrm{~Hz}, 1 \mathrm{H}), 4.08(\mathrm{~s}, 1 \mathrm{H}), 4.02(\mathrm{~s}$, 1H), $2.34(\mathrm{~s}, 3 \mathrm{H}), 2.28(\mathrm{~s}, 3 \mathrm{H}) ;{ }^{13} \mathrm{C} \mathrm{NMR}\left(\mathrm{CDCl}_{3}\right): \delta 177.7,177.2,162.4,161.8,157.2$, $152.17,148.9,136.7,134.4,130.6,129.8,129.6,129.5,128.8,128.7,128.5,127.8$ $127.4,126.4,125.9,123.1,121.8,111.8,109.9,109.7,109.6,34.8,34.5,32.7,21.3,21$, 19.4. GC-MS: m/z 200, 185, 171, 128, 115, 91, 77.

5-(p-Methyl)benzylfuran-2-carbaldehyde: ${ }^{1} \mathrm{H}$ NMR $\left(\mathrm{CDCl}_{3}\right): \delta 9.55(\mathrm{~s}, 1 \mathrm{H}), 7.11-7.18$ (m, 5H), $6.19(\mathrm{~d}, J=2.8 \mathrm{~Hz}, 1 \mathrm{H}), 6.18(\mathrm{~d}, \mathrm{~J}=2.5 \mathrm{~Hz}, 1 \mathrm{H}), 4.04(\mathrm{~s}, 2 \mathrm{H}), 2.35(\mathrm{~s}, 3 \mathrm{H}), 2.28(\mathrm{~s}$, $3 \mathrm{H}) ;{ }^{13} \mathrm{C} \mathrm{NMR}\left(\mathrm{CDCl}_{3}\right): \delta 177.2,162.4,152.2,136.7,133,129.5,128.8,123,109.6,34.5$, 21. GC-MS: m/z 200, 185, 171, 128, 115, 91, 77.

5-(2,3-and 3,5-dimethyl)benzylfuran-2-carbaldehyde.: $1 \mathrm{H} N M R(300 \mathrm{MHZ}, \mathrm{CDCl}$ ): $\delta$ $9.44(\mathrm{~s}, 2 \mathrm{H}), 6.85-7.11(\mathrm{~m}, 6 \mathrm{H}), 6.10(\mathrm{~d}, \mathrm{~J}=2.8 \mathrm{~Hz}, 1 \mathrm{H}), 5.95(\mathrm{~d}, \mathrm{~J}=2.5 \mathrm{~Hz}, 1 \mathrm{H}), 3.99$ (s, 1H), $3.9(\mathrm{~s}, 1 \mathrm{H}), 2.21(\mathrm{~s}, 3 \mathrm{H}), 2.16(\mathrm{~s}, 3 \mathrm{H}), 2.09(3 \mathrm{H}) ; 13 \mathrm{C} \mathrm{NMR}(75 \mathrm{MHz}, \mathrm{CDCl} 3) \delta$ $177.24,162.58,162.27,152.15,137.37,136.99,135.34,135.08,134.27,133.48$, $130.16,129.99,129.15,127.87,126.24,125.79,123.15,109.73,109.62,34.46,33.35$, 20.65, 19.72, 19.35, 15.34. GC-MS: m/z 214, 199, 185, 142, 115.

5-(o and p-methoxy)benzylfuran-2-carbaldehyde: ${ }^{1} \mathrm{H} \mathrm{NMR}\left(300 \mathrm{MHz}, \mathrm{CDCl}_{3}\right) \delta 9.44(\mathrm{~s}$, 2H), 7.16-6.74 (m, 8H), $6.08(\mathrm{~d}, \mathrm{~J}=2.7 \mathrm{~Hz}), 6.04(\mathrm{~d}, \mathrm{~J}=2.6 \mathrm{~Hz}), 3.71(\mathrm{~s}, 1 \mathrm{H}), 3.69(\mathrm{~s}, 1 \mathrm{H})$. ${ }^{13} \mathrm{C}$ NMR $\left(75 \mathrm{MHz}_{\mathrm{CDCl}}\right) \delta 177.15,158.23,134.59,130.45,130.20,129.94,129.66$, $129.44,128.53,128.13,124.67,120.69,120.65,114.21,113.91,113.82,113.72$, $113.63,110.64,109.56,108.71,106.44,55.40,55.29,55.23,55.13,49.29,34.05,33.69$, 29.20. GC-MS: m/z 216, 187, 144, 115. 
5-(mesityl)benzylfuran-2-carbaldehyde: ${ }^{1} \mathrm{H}$ NMR $\left(300 \mathrm{MHz}, \mathrm{CDCl}_{3}\right) \delta 9.45(\mathrm{~s}, 1 \mathrm{H} ; 7.04-$ $7.03(\mathrm{~d}, J=3 \mathrm{~Hz}, 1 \mathrm{H}), 6.82(\mathrm{~s}, 2 \mathrm{H}), 5.84-5.83(\mathrm{~d}, J=3 \mathrm{~Hz}, 1 \mathrm{H}), 3.97(\mathrm{~s}, 2 \mathrm{H}), 2.21(\mathrm{~s}, 3 \mathrm{H})$, $2.19(\mathrm{~s}, 6 \mathrm{H}) .{ }^{13} \mathrm{C} \mathrm{NMR}\left(75 \mathrm{MHz}, \mathrm{CDCl}_{3}\right) \delta 177.07,161.94,152.11,136.82,136.65$, 129.68, 129.13, 109.09, 28.65, 20.88, 19.93. GC-MS: m/z 228, 182, 143, 91.

5,5-oxy(bis-methylene)-2-furaldehyde: ${ }^{1} \mathrm{H}$ NMR (300 MHz, $\left.\mathrm{CDCl} 3\right): \delta 9.56(\mathrm{~s}, 2 \mathrm{H}), 7.15-$ $7.14(\mathrm{~d}, J=3 \mathrm{~Hz}, 1 \mathrm{H}), 6.50-6.49(\mathrm{~d}, J=3 \mathrm{~Hz}, 1 \mathrm{H}), 4.56(\mathrm{~s}, 4 \mathrm{H}) .{ }^{13} \mathrm{C} \mathrm{NMR}\left(75 \mathrm{MHz}, \mathrm{CDCl}_{3}\right)$ $\delta$ 177.7, 157.21, 152.81, 121.77, 111.83, 64.63. GC-MS: m/z 234, 206, 125, 109, 81.

\subsection{Hydrodeoxygenation process}

A physical mixture of $5.34 \mathrm{~g}$ of $3 \mathrm{wt} \% \mathrm{Pt}$ on active carbon and $1.34 \mathrm{~g}$ of $3 \mathrm{wt} \% \mathrm{Pt}$ on $\mathrm{TiO}_{2}$ as, was placed in the stainless steel tubular reactor with an inner diameter of $7.7 \mathrm{~mm}$ and a length of $38 \mathrm{~cm}$. Before the reaction the metal catalyst was activated(reduced) applying a hydrogen pressure of 40 bar and hydrogen flow of $450 \mathrm{ml} / \mathrm{min}$ at $400{ }^{\circ} \mathrm{C}$ during $1 \mathrm{~h}$.

The reactor pressure was controlled with a Swagelok back-pressure regulator. Hydrogen gas flow to the reactor was controlled using a Bronkhorst EL-FLOW select mass flow controller. A mixture of 5-(o-, m- and p-methyl)benzylfuran-2-carbaldehyde (10.09 g) was pumped to the reactor with a Gilson 305 pump equipped with a HPLC pump head and mixed with the hydrogen flow before entering the reactor and a rate of $0.1 \mathrm{ml} / \mathrm{min}$ with the same hydrogen flow and pressure as during the activation step. The reaction temperature was $65^{\circ} \mathrm{C}$ and the entry of the reactor with a gradient to the middle of the reactor of $120{ }^{\circ} \mathrm{C}$ and $350{ }^{\circ} \mathrm{C}$ in the second half of the reactor. 
Two liquid phases (aqueous and organic) were collected in a two tanks at room temperature at the exit of the reactor with a total weight $8.8 \mathrm{~g}$, being the aqueous phase $15 \%$ and the organic phase $85 \%$.

Gaseous samples were taken after the back-pressure regulator (4\%) and analyzed by GC. The mass balance was $90.6 \%$.

\subsection{Simulated distillation}

The organic phase were analyzed by simulated distillation and was performed using ASTM D2887 method in order to study the boiling range distribution of different product samples at different temperatures using a BRUKER 450 gas chromatograph. A capillary column CP SimDis (10 m x $0.53 \mathrm{~mm}$ diameter $\times 2.65 \mu \mathrm{m}$ ) was used to separate hydrocarbons present in different product samples based on the order of their boiling range. To identify different boiling fractions, a calibration curve was used which was obtained by chromatographic analysis of a mixture of known boiling point compounds. A flame ionization detector (FID) was used to detect different boiling ranges using helium as a carrier gas at a flow rate of $30 \mathrm{ml} / \mathrm{min}$. The hydrogen and air flow were maintained at 35 and $400 \mathrm{ml} / \mathrm{min}$, respectively. The detector temperature and oven final temperature were maintained at 375 and $380{ }^{\circ} \mathrm{C}$, respectively.

\section{Analysis of the products obtained in the hydrodeoxygenation process}

The gas chromatographic analysis of the product mixtures of the hydrodeoxygenation were analyzed by two dimensional gas chromatography with hydrogen as carrier gas on an Agilent Technologies GC 7890A equipped with a flame ionization detector (FID), two capillary columns, and a flow modulator. The first column was an Innowax column (30 m, $0.25 \mathrm{~mm}$ inner diameter, $250 \mu \mathrm{m}$ film) with a hydrogen flow of $0.3 \mathrm{ml} / \mathrm{min}$ and the second column was a DB-5 column ( $5 \mathrm{~m}, 0.25 \mathrm{~mm}$ inner diameter, $250 \mu \mathrm{m}$ film) 
with a hydrogen flow of $24 \mathrm{ml} / \mathrm{min}$. The modulator period was $1.0 \mathrm{~s}$ for collection and $0.12 \mathrm{~s}$ for flushing the collection channel. As $2 \mathrm{D}$ analysis software GC Image from Zoex corporation was used.

Blobs (peaks) were classified as $C_{9}$ to $C_{31}$ saturated (linear, naphthenes, polynaphthenes), as low weight hydrocarbons $\left(C_{4}\right.$ to $\left.C_{8}\right)$, monoaromatics, diaromatics, triaromatics and polar compounds.

Gas samples from the hydrodecarboxylation were analyzed with a Varian 3800 GC equipped with three detectors.

Two detectors were thermal conductivity detectors (TCD) for the analysis of $\mathrm{H}_{2}(2.5 \mathrm{~m}$ molecular sieves $13 \mathrm{X}$ column). The third detector was a flame ionization detector (FID) for the analysis of $\mathrm{C}_{1}$ to $\mathrm{C}_{6}$ hydrocarbons separated on a $50 \mathrm{~m}$ Plot $/ \mathrm{Al}_{2} \mathrm{O}_{3}$ column.

\section{Acknowledgements}

Financial support by Consolider-Ingenio 2010 (project MULTICAT), Spanish MICINN Project CTQ-2011-27550), Generalitat Valenciana (Prometeo program) and Program Severo Ochoa are gratefully acknowledged.This work was supported by Consolider . KSA is grateful to ITQ for a doctoral grant.

\section{References}

1. a)G. W. Huber, S. Iborra and A. Corma, Chem. Rev., 2006, 106, 4044; b) J. Holmgren,

C. Gosling, R. Mariangeli, T. Marker, G. Faraci, C. Perego, Hydrocarbon Proc., 2007, 86, 67.

2. M.J. Climent, A. Corma, and S. Iborra, Green Chem., 2014, 16, 516.

3. Y.T. Cheng, J. Jae, Jian S. Wei F., and G.W. Huber Angew. Chem. Int. Ed., 2012, 51, 1387. 
4. P. Gullon, A. Romani, C. Vila, G. Garrote, and J.C. Parajo, Biofuels, Bioproducts \& Biorefining, 2012, 6(2), 219.

5. P. Dominguez de Maria, J. Chem. Technol. Biotechnol., 2014, 89, 11.

6. a) T. Werpy and G. R. Petersen, Top Value Added Chemicals from Biomass. Volume I. Results of Screening for Potential Candidates from Sugars and Synthesis Gas, U.S.D. Energy, 2004.; b) J. J. Bozell and G. R. Petersen, Green Chem., 2010, 12, 539.

7. a)M.J. Climent, A. Corma, S. Iborra, Green Chem., 2011, 13, 520; b) A. A. Rosatella, S.

P. Simeonov, R. F. M. Frade and C. A. M. Afonso, Green Chem., 2011, 13, 754.

8. B. F. M. Kuster, L. M. and Tebbens, Carbohydr. Res. 1977, 54, 159

9. a)X. Tong, Y. Ma, Y. Li, Appl. Catal. A General 2010, 385, 1; b) R.J. van Putten, J.C. van der Waaal, E. de Jong, C.B. Rasrendra, H.J. Heeres and J.G. de Vries, Chem. Rev. 2013, 113, 1499; c) S.P. Teong, G. Yi, Y. Zhang, Green Chem 2014, 16, 2015.

10. Y. Nakamura and S. Morikawa, Bull., Chem. Soc., Jpn., 1980, 53, 3705.

11. a) Y. Roman-Leshkow, J.N. Chheda, and J.A. Dumesic, Science 2006, 312, 1933; b)B. Saha, and M.M. Abu-Omar, Green Chem. 2014, 16, 24.

12. S. Frenzel, S. Peters, T. Rose and M. Kunz, Industrial Sucrose, In R. Höfer ed., Sustainable Solutions for Modern Economies, RSC Green Chemistry, No 4, RSC Publ., Cambridge (2009), p. 264-299.

13 Biochem AVA (2014) First Industrial Production for Renevable 5-HMF. Available at http://www.ava-biochem.com/media/downloads.EN/press_releases/First_Industrial. Production.For.Renewable.5-HMF.pdf.Accesed April 16, 2014.

14. J. Vyskocil, and A. Kruse, DE102011053034, 2011.

15 J.N. Chheda, G.W. Huber, and J.A. Dumesic, Angew. Chem. Int. Ed. 2007, 46, 7164.

16. J. Q. Bond, D. M. Alonso, D. Wang, R. M. West and J. A. Dumesic, Science, 2010, $327,1110$.

17 A. Corma, M. Renz, and C. Schaverien, ChemSusChem 2008,1, 739.

18. J. C. Serrano-Ruiz, D. J. Braden, R. M. West and J. A. Dumesic, Appl. Catal. BEnviron., 2010, 100, 184.

19. A. Pulido, B. Oliver-Tomas, M. Renz, M. Boronat, and A. Corma, ChemSusChem 2013, 6, 141. 
20 E.L. Kunkes, D.A. Simonetti, R.M. West, J.C. Serrano-Ruiz, C.A. Gartner, and J.A. Dumesic, Science, 2008, 322, 417.)

21. A. Corma, O. de la Torre, M. Renz and N. Villandier, Angew. Chem. Int. Ed., 2011, 50, 2375.

22. A. Corma, O. de la Torre and M. Renz, ChemSusChem, 2011, 4, 1574.

23. A. Corma, O. de la Torre and M. Renz, Energ. Environ. Sci., 2012, 5, 6328.

24. G. W. Huber, J. N. Chheda, C. J. Barrett and J. A. Dumesic, Science, 2005, 308, 1446.

25. C. J. Barrett, J. N. Chheda, G. W. Huber and J. A. Dumesic, Appl. Catal. B-Environ., 2006, 66, 111.

26. J. Dumesic, G.W. Huber, N.J.Chheda and C.J. Barret, WO Pat. 2007103858, 2007.

27. K. Mertins, J. Kischel, A. Zapf, and M. Beller, Angew. Chem. Int. Ed. 2005, 44, 3913. 28. X. Zhou and T. Rauchfuss, ChemSusChem 2013, 6, 383.

29. A. Onorato, C. Pavlik, M.A. Invernale, I.D. Berghorn, G. A. Sotzing, M.D. Morton, and M. B. Smith, Carbohydrate Res., 2011, 346, 1662.

30. a) A. M.F. Bidart, A. P.S. Borges, L. Nogueira, E. R. Lachter, and C. J. A. Mota, Catal. Lett., 2001, 75, 155; b) K. Okumura, K. Nishigaki, and M. Niwa, Microporous Mesoporous Mater. 2001, 44-45, 509; c) P. Kalita, N. M. Gupta, and R. Kumar, J. Catal., 2007, 245, 338; d) Y. Sun, and R. Prins, Appl. Catal., A: General, 2008, 336, 11.

31. a) M. J. Climent, A. Corma, H. Garcia, and J. Primo, Appl. Catal. 1989, 51, 113; b) S. Al-Khattaf, and M.A. Ali, and J. Cejka Recent Development in Transformation of Aromatic Hydrocarbons over Zeolites, in Zeolites and Catalysis 2010, 2, 623-648, ed. J. Cejka, A. Corma, and S. Zones, Wiley-VCH, Weinheim; c) D. Verboekend, and J. PerezRamirez, Catal. Sci. Technol. 2011, 1,879; d) R. Gounder, and E. Iglesia, Chem. Commun. 2013, 49, 3491.

32 T. Yamato, C. Hidezhima, G.K.S. Prakash and G. Olah, J. Org. Chem., 1991, 56, 2089. 33. a)) A. Corma, C. Zicovich-Wilson, and P. Viruela, J. Phys. Org. Chem. 1994, 7, 364; b) S. Van der Beken, E. Dejaegere, K. A. Tehrani, J.S. Paul, P.A. Jacobs, G.V. Baron, and J. F. M Denayer, J. Catal., 2005, 235, 128.

34 L.A. Pine, P.J. Maher, and W.A. Wacher, J. Catal., 1984, 85, 466.

35. D. Verboekend, G. Vile and J. Perez-Ramirez, Adv. Funct. Mater., 2012, 22, 916.

36. J. Klinowski, J.M. Thomas, C.A. Fyfe and G.C. Gobbi, Nature, 1982, 296, 533. 
37. M. E. Leonowicz, J. A. Lawton, S. L. Lawton, and M. K. Rubin, Science, 1994, 264, 1910.

38. a) F. Cavani, V. Arrigoni, R. Ghezzi, G. Bellusi, CA Pat. 2030067 (1991); b) A. Corma, V. Martínez-Soria, E. Schnoeveld, J. Catal., 2000, 192, 163.

39. A. Corma, V. Fornes, S. B. Pergher, T. Maesen, J. G. Buglass, Nature 1998, 396, 353.

40. S. Zanardi, A. Alberti, G. Cruciani, A. Corma, V. Fornes, and M. Brunelli, Angew. Chem. Int. Ed., 2004, 43, 4933.

41. A. Corma, U. Diaz, T. García, G. Sastre, and A. Velty, J. Am. Chem. Soc. 2010, 132, 15011)

42. U. Diaz, V. Fornes, and A. Corma, Microporous and Mesoporous Mater. 2006, 90, 73.

43. J. Aguilar, S.B.C. Pergher, C. Detoni, A. Corma, F.V. Melo, and E. Sastre, Catal. Today, 2008, 133-135, 667.

44. H. J Lugo, G. Ragone, and J. Zambrano, Ind. Eng. Chem. Res. 1999, 38, 2171.

45. C. T. Kresge, M. E. Leonowicz, W. J. Roth, J. C. Vartulli, J. S. Beck, Nature 1992, 359, 710.

46. C.A. Emeis J. Catal. 1993, 141, 347.

47. D. W. Breck and E. Flanigen, Molecular sieves, Society of Chemical Industry, 1968, p. 47.

48. H. Fichtner-Schmittler, U. Lohse, G. Engelhardt and V. Patzelova, Cryst. Res. Technol., 1984, 19, K1. 


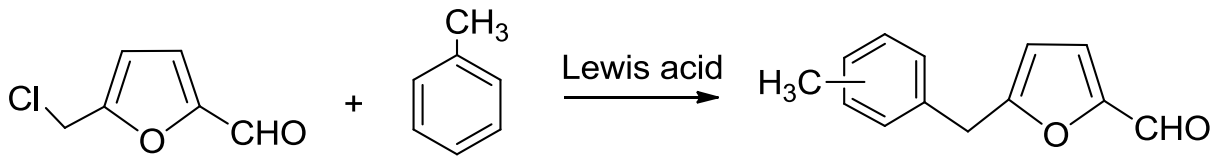

Scheme 1a<smiles>Cc1ccccc1CCCCCCc1ccc(C=O)o1</smiles>

Scheme $1 b$

Scheme 1. Synthesis of alkylated products of toluene from 5-chloromethyl-2-furfural (Scheme 1a) and from HMF (Scheme 1b) 


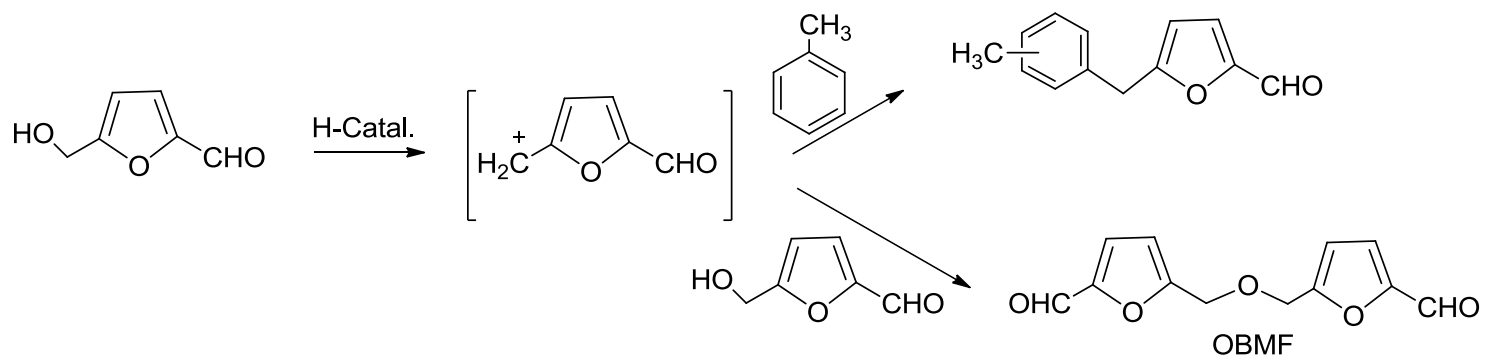

Scheme 2. Products obtained (5-alkylated and OBMF) in the alkylation reaction of toluene with HMF. 


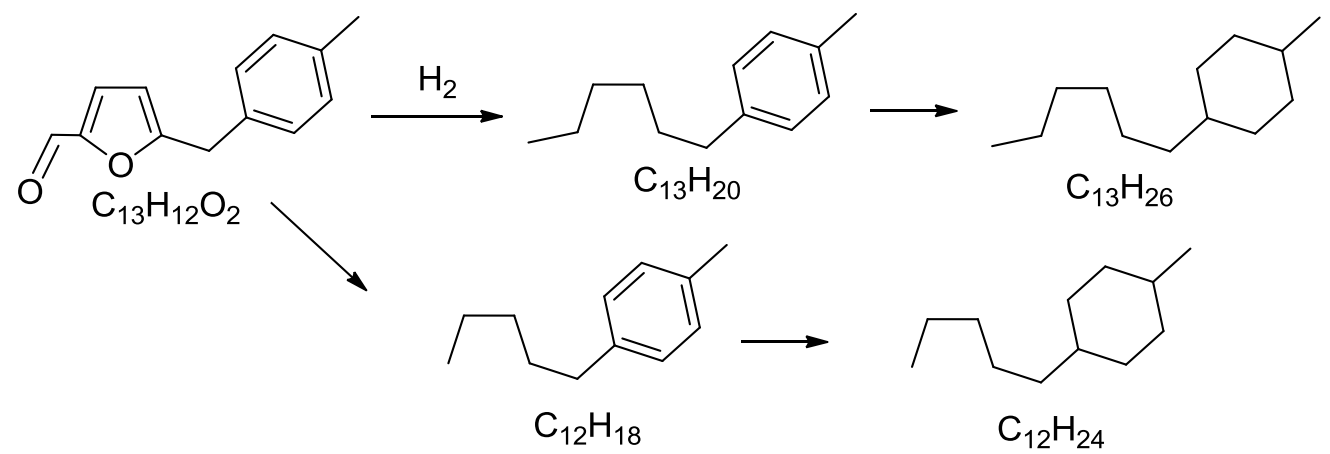

Scheme 3. Main detected products after hydrodeoxygenation of 5-(o-, m- and $p$ methyl)benzylfuran-2-carbaldehyde in the presence of $\mathrm{Pt} / \mathrm{C}$ and $\mathrm{Pt} / \mathrm{TiO}_{2}$ catalysts 


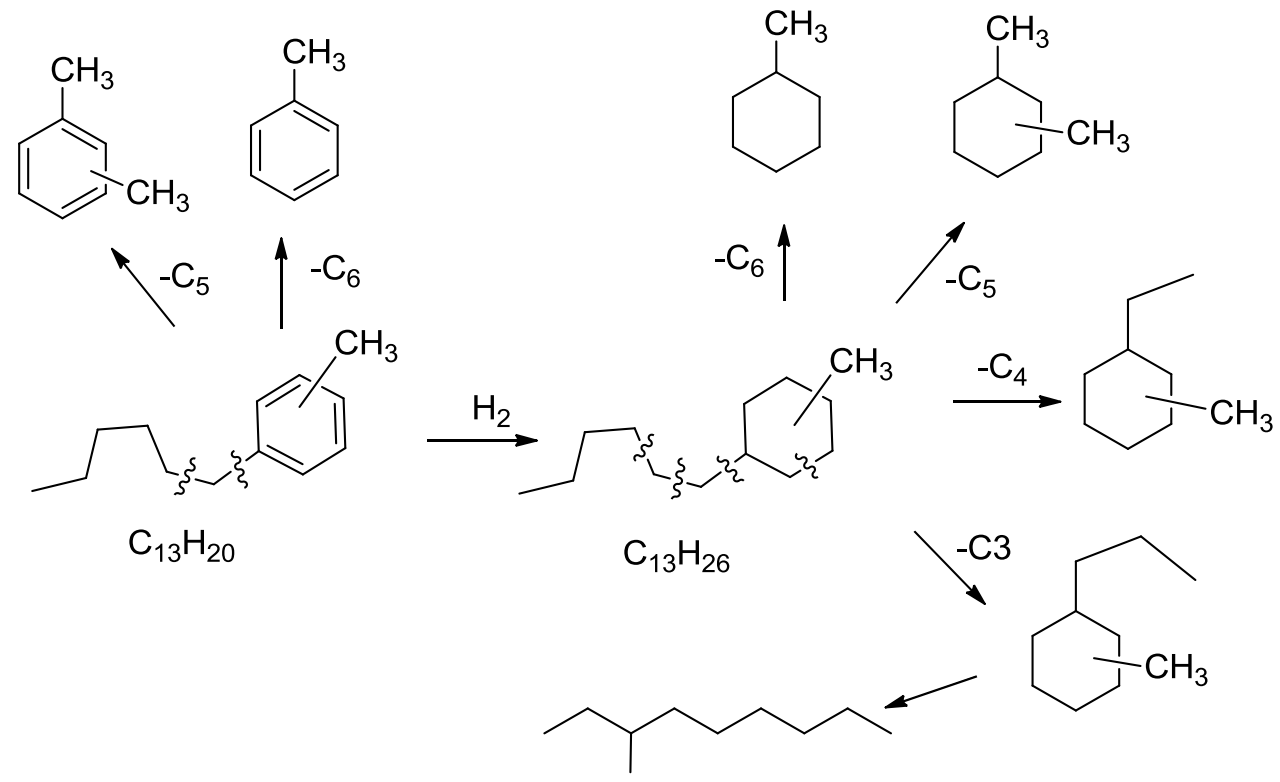


Scheme 4. Main detected products in the range C6-C10 after hydrodeoxygenation of 5(o-, $\mathrm{m}$ - and p-methyl)benzylfuran-2-carbaldehyde in the presence of $\mathrm{Pt} / \mathrm{C}$ and $\mathrm{Pt} / \mathrm{TiO}_{2}$ catalysts

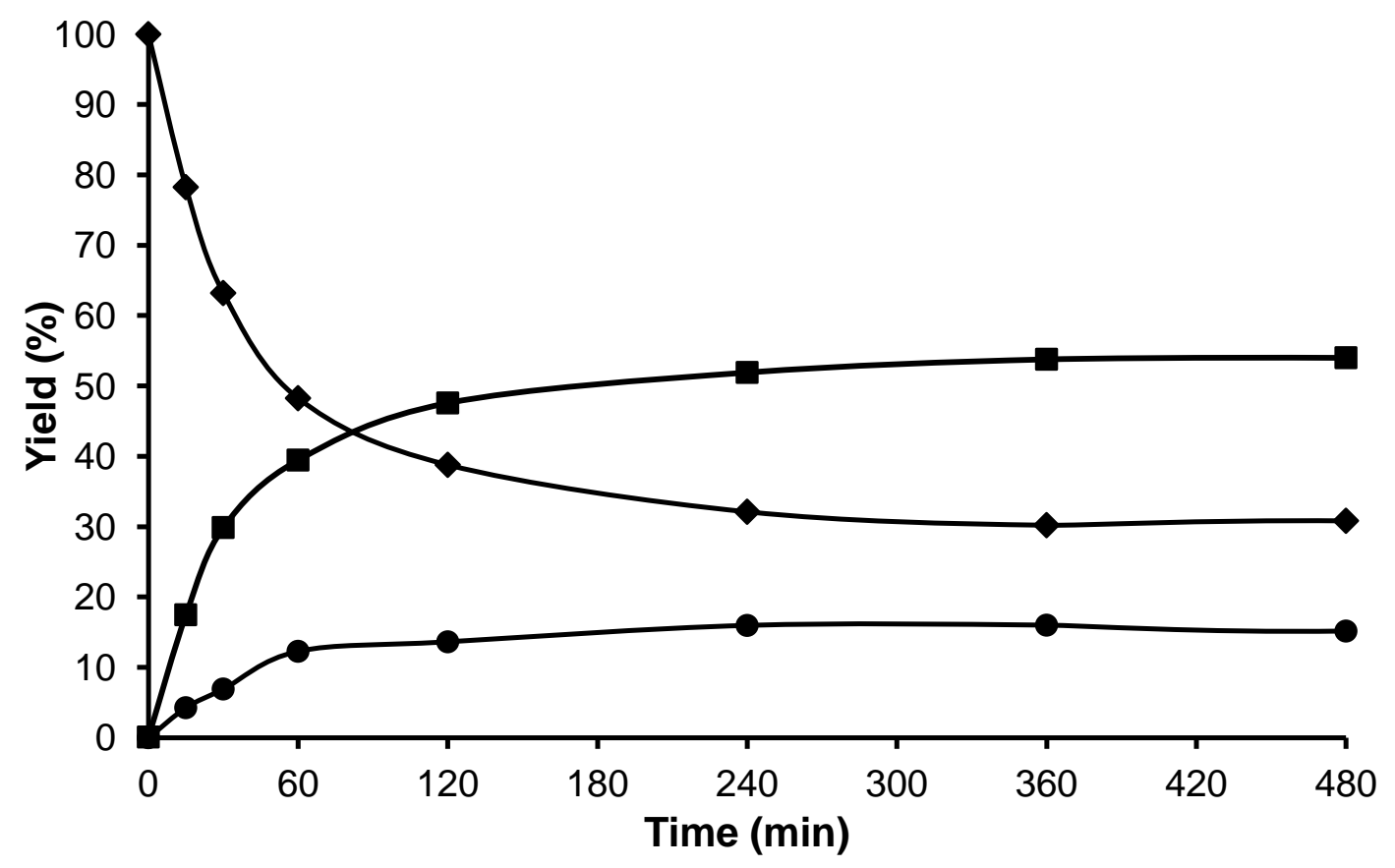

Figure 1. Kinetic curves of alkylation of toluene $(25 \mathrm{ml})$ with $\mathrm{HMF}(0.5 \mathrm{mmol})$ in the presence of HBeta ( $25 \mathrm{wt} \%$ respect HMF) at reflux temperature under nitrogen atmosphere: HMF $(\downarrow)$, 5- alkylated products: ortho, meta, para isomers ( $\mathbf{\square})$ and OBMF (•). 


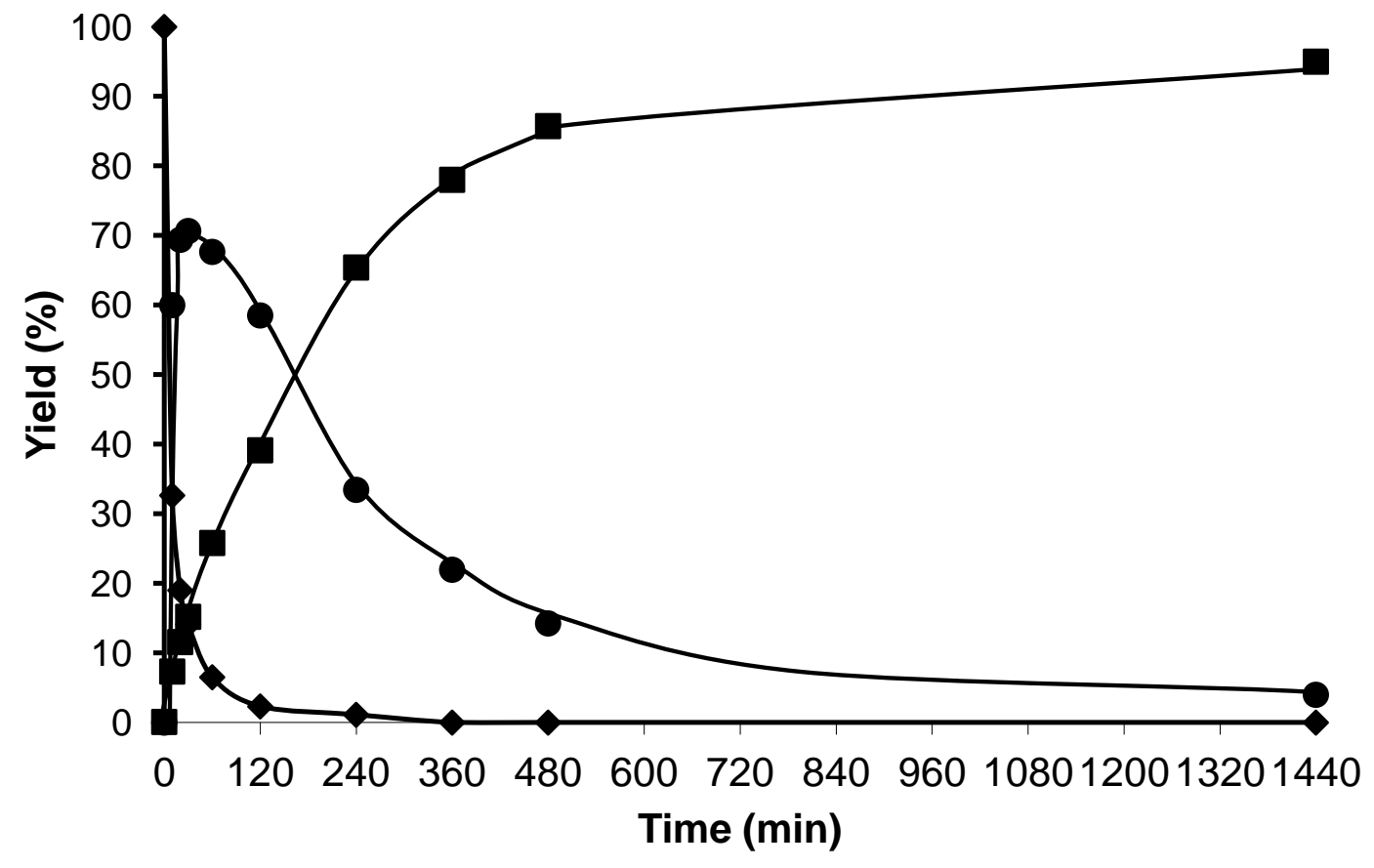

Figure 2. Results of alkylation of toluene $(25 \mathrm{ml})$ with HMF $(0.5 \mathrm{mmol})$ in the presence of p-toluenesulfonic acid (18 wt\% respect HMF) at reflux temperature under nitrogen atmosphere: HMF ( $\downarrow)$, 5-alkylated products: ortho, meta, para isomers ( $\boldsymbol{\square})$ and OBMF $(\bullet)$. 


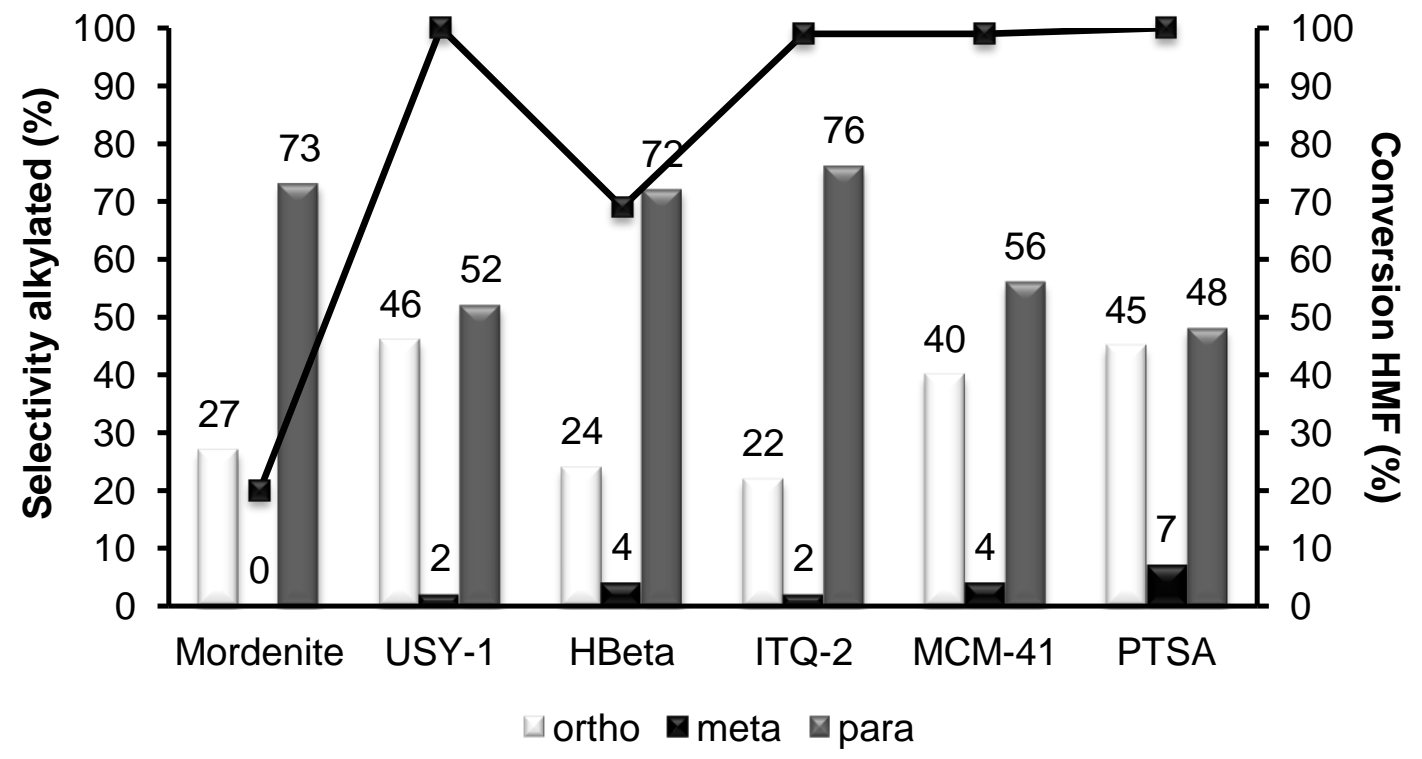

Figure 3. Results of HMF conversion and selectivity to ortho, meta and para alkylated isomers obtained in the alkylation of toluene with HMF over different acid catalysts at $8 \mathrm{~h}$ of reaction. 


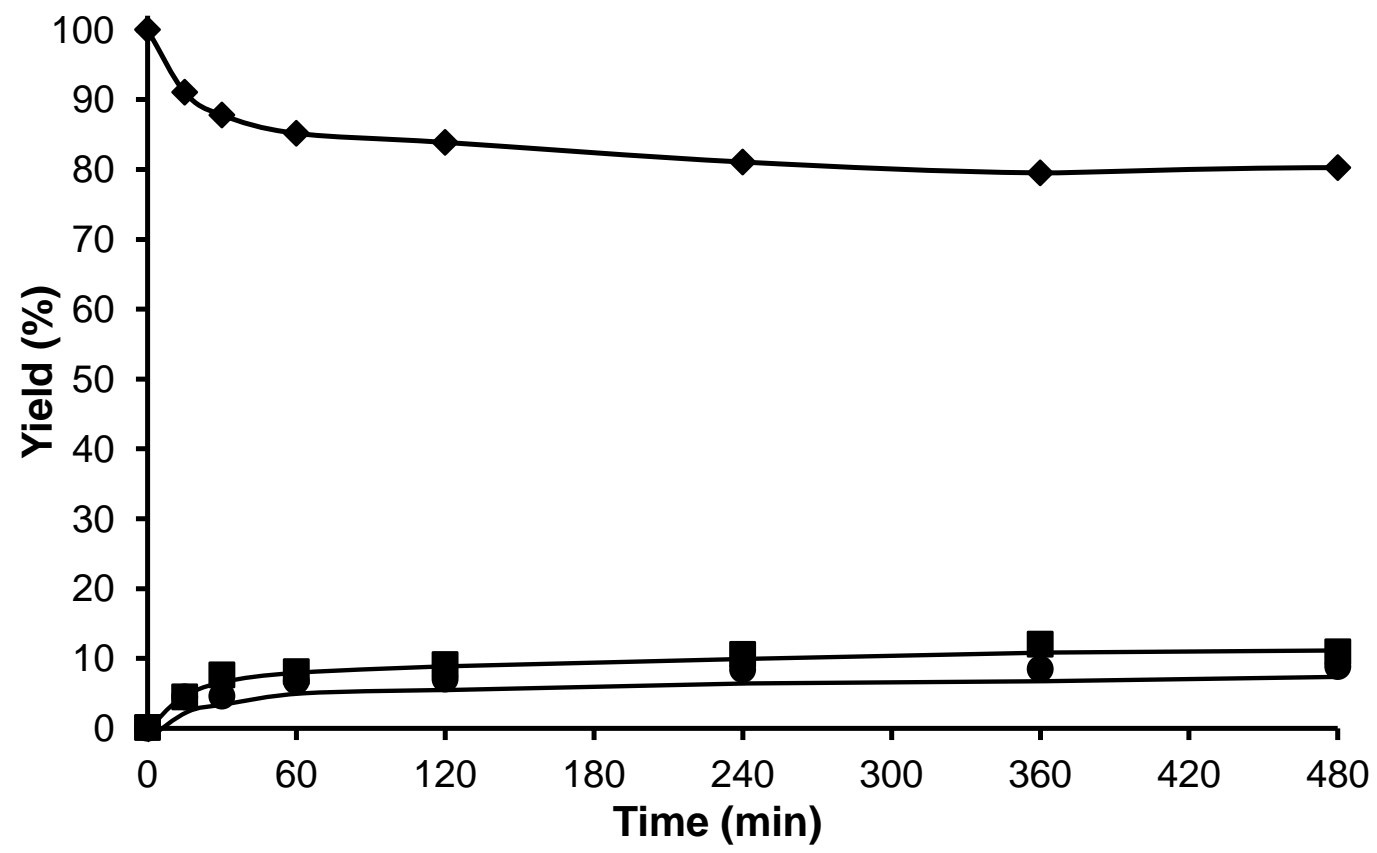

Figure 4. Kinetic curves of alkylation of toluene $(25 \mathrm{ml})$ with HMF $(0.5 \mathrm{mmol})$ in the presence of Mordenite ( $25 \mathrm{wt} \%$ respect HMF) at reflux temperature under nitrogen atmosphere: HMF ( $\bullet)$, 5- alkylated products: ortho, meta, para isomers ( $\square$ ) and OBMF $(\bullet)$. 


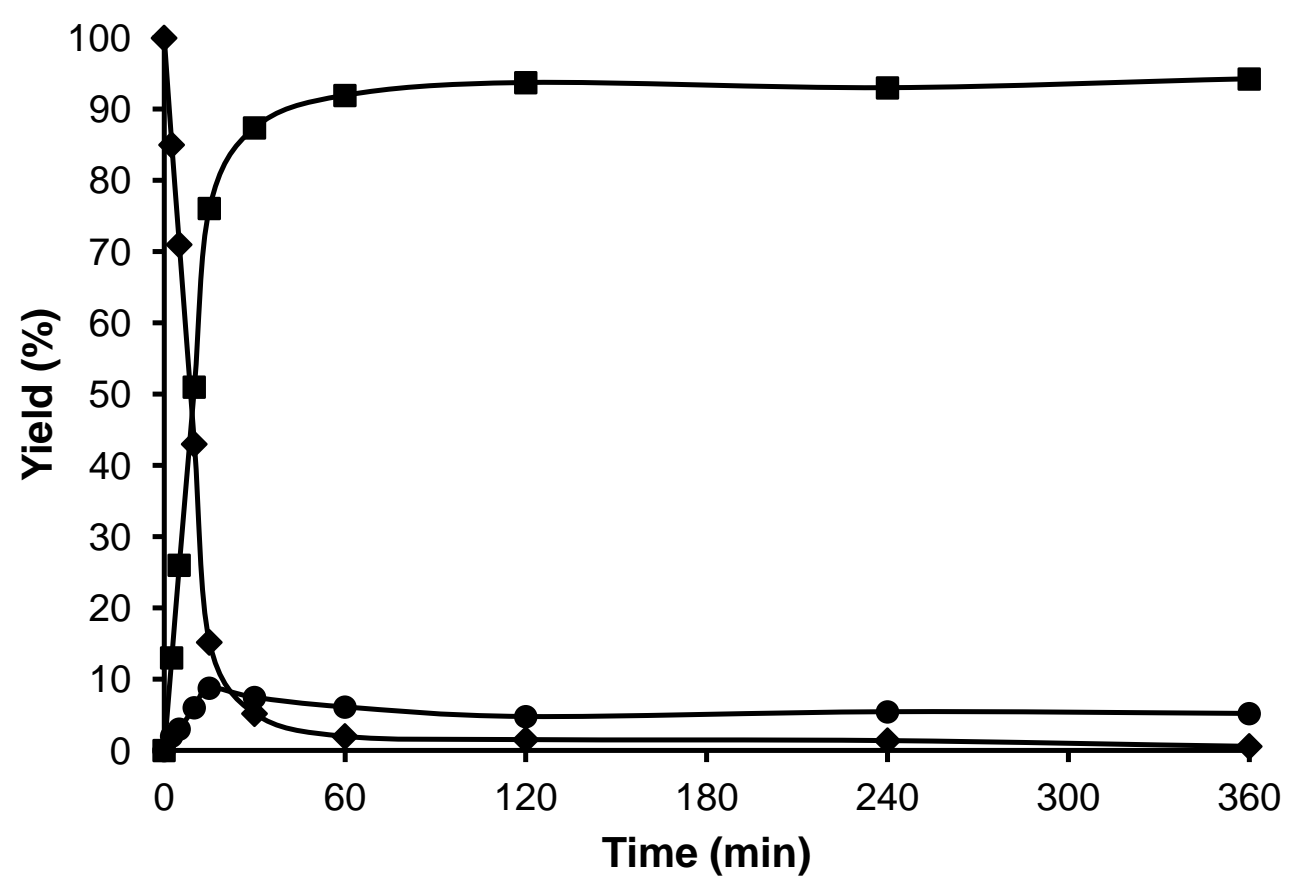

Figure 5. Kinetic curves of alkylation of toluene $(25 \mathrm{ml})$ with $\mathrm{HMF}(0.5 \mathrm{mmol})$ in the presence of USY-720 ( $25 \mathrm{wt} \%$ respect HMF) at refluxed temperature under nitrogen atmosphere: HMF $(\downarrow)$, 5-alkylated products: ortho, meta, para isomers ( $\mathbf{\square})$ and OBMF $(\bullet)$. 


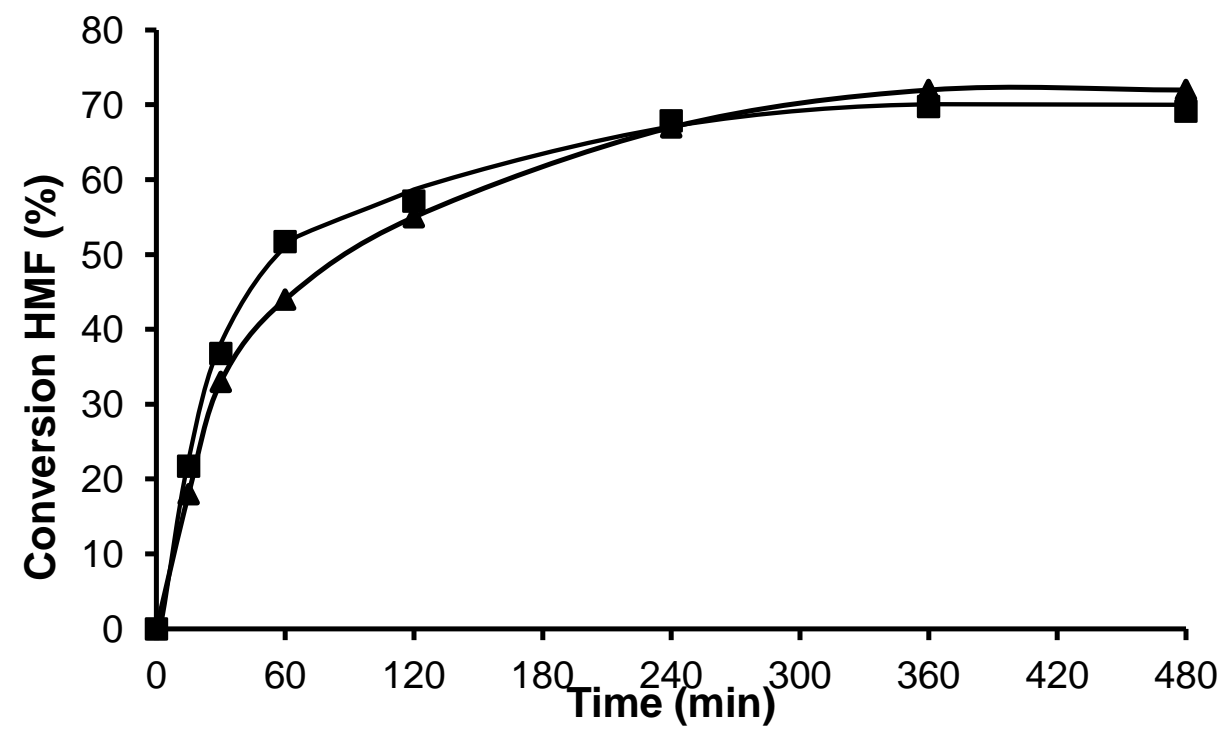

Figure 6a. Conversion versus time plot for the alkylation of toluene $(25 \mathrm{ml})$ with HMF $(0.5 \mathrm{mmol})$ in the presence of Beta $1^{\text {st }}$ cycle $(\boldsymbol{\square})$ and $2^{\text {nd }}$ cycle (after calcination) ( $\left.\mathbf{\Delta}\right)(25$ $w t \%$ respect $\mathrm{HMF}$ ) at refluxed temperature and nitrogen atmosphere.

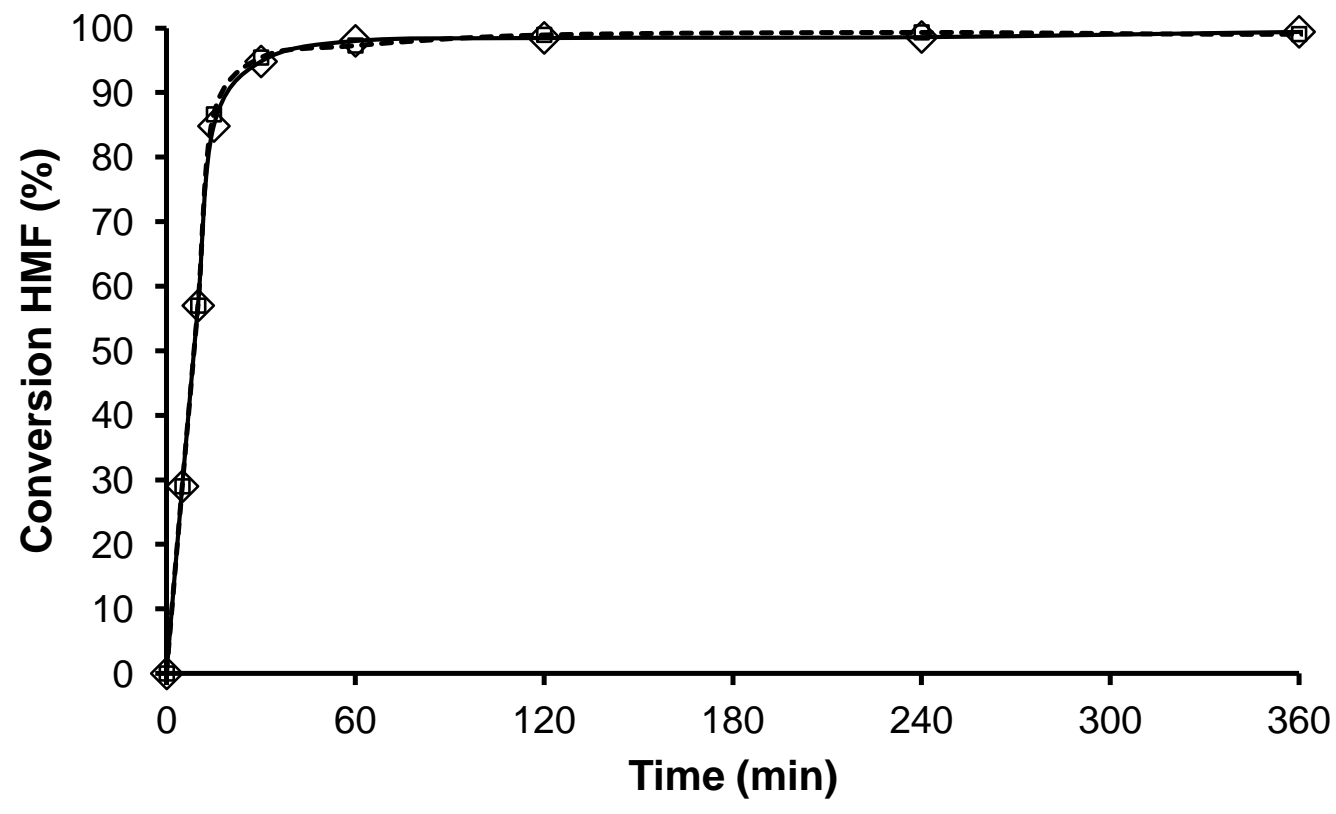


Figure $6 \mathbf{b}$. Conversion versus time plot for the alkylation of toluene $(25 \mathrm{ml})$ with HMF $(0.5 \mathrm{mmol})$ in the presence of USY-720. $1^{\text {st }}$ cycle (-----) and $2^{\text {nd }}$ cycle (after calcination) $(\diamond)$ ( $25 \mathrm{wt} \%$ respect HMF) at reflux temperature under nitrogen atmosphere.

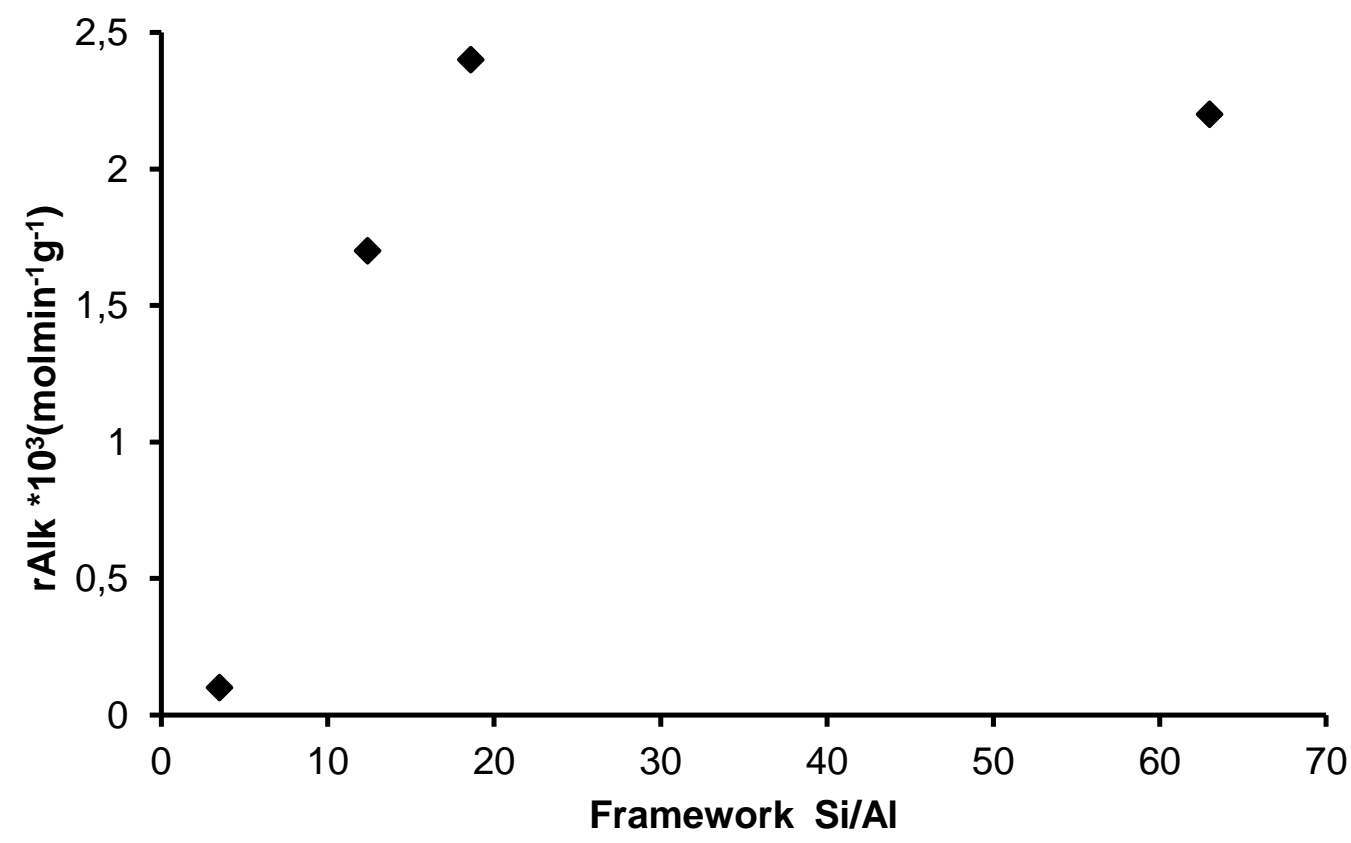

Figure 7. Rate of appearance of alkylated compounds versus FAL content of different USY samples. 


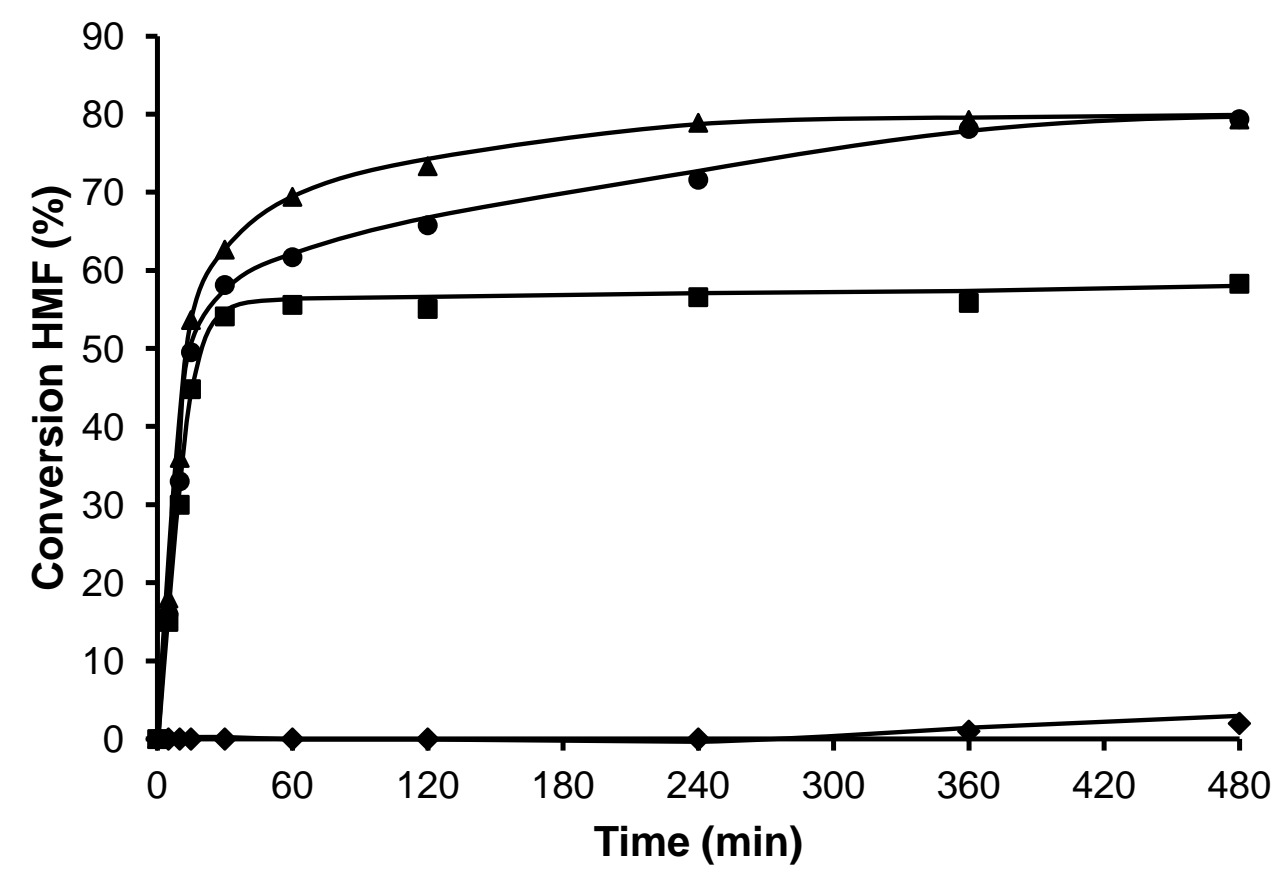

Figure 8. Conversion versus time plot for the alkylation of toluene $(25 \mathrm{ml})$ with $\mathrm{HMF}$ ( $0.5 \mathrm{mmol})$ in the presence of different USY samples (10 wt\% respect HMF) at reflux

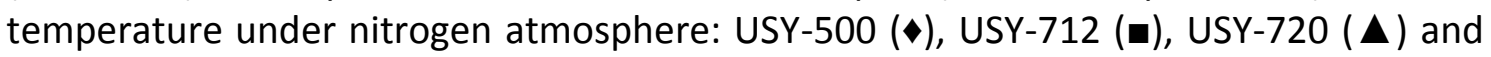
USY-760 (•). 


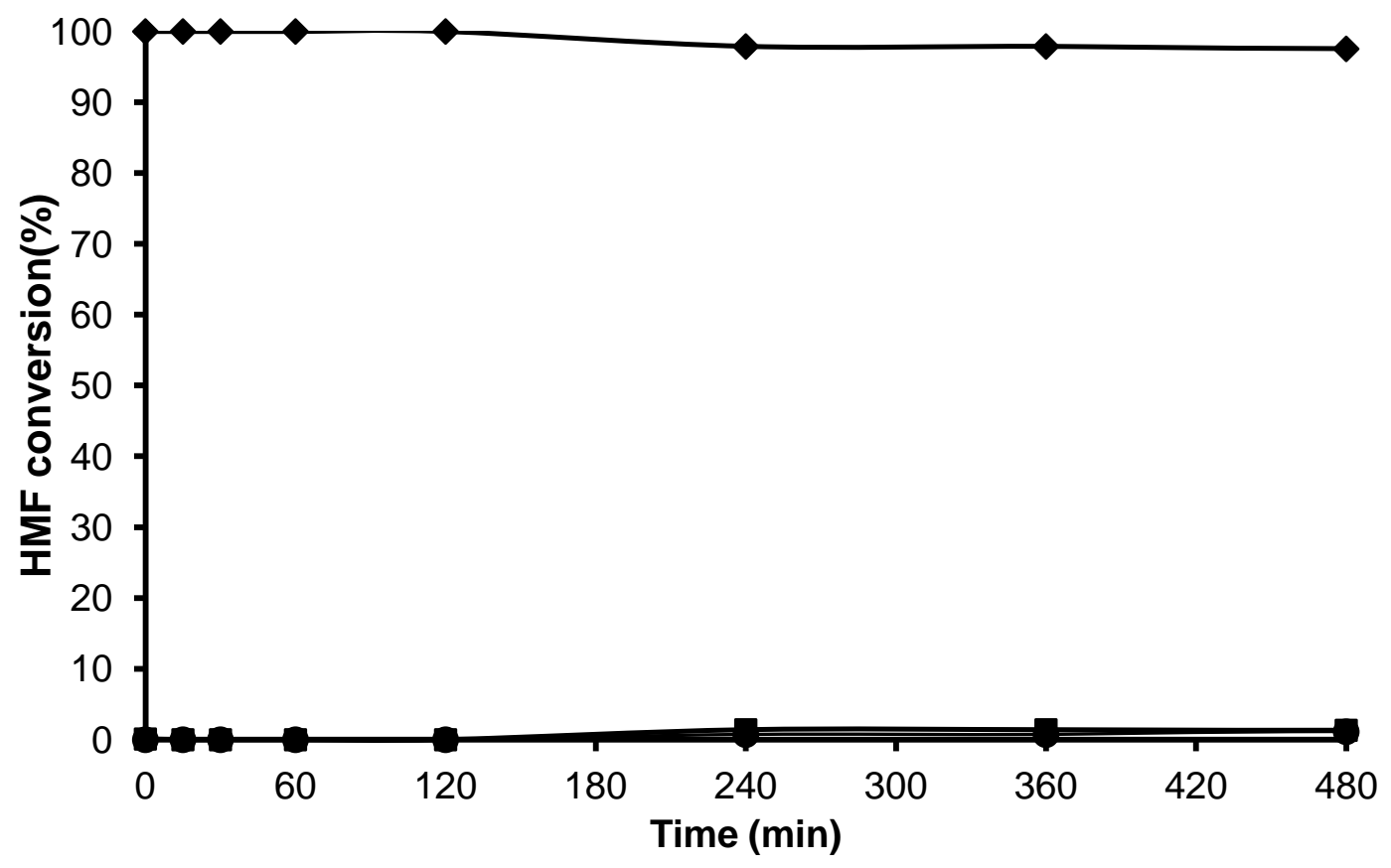

Figure 9. Kinetic curves of alkylation of toluene $(25 \mathrm{ml})$ with HMF $(0.5 \mathrm{mmol})$ in the presence of USY-300 (25 wt\% respect HMF) at reflux temperature under nitrogen atmosphere: HMF $(\downarrow)$, 5- alkylated products: ortho, meta, para isomers ( $\square$ ) and OBMF (•). 


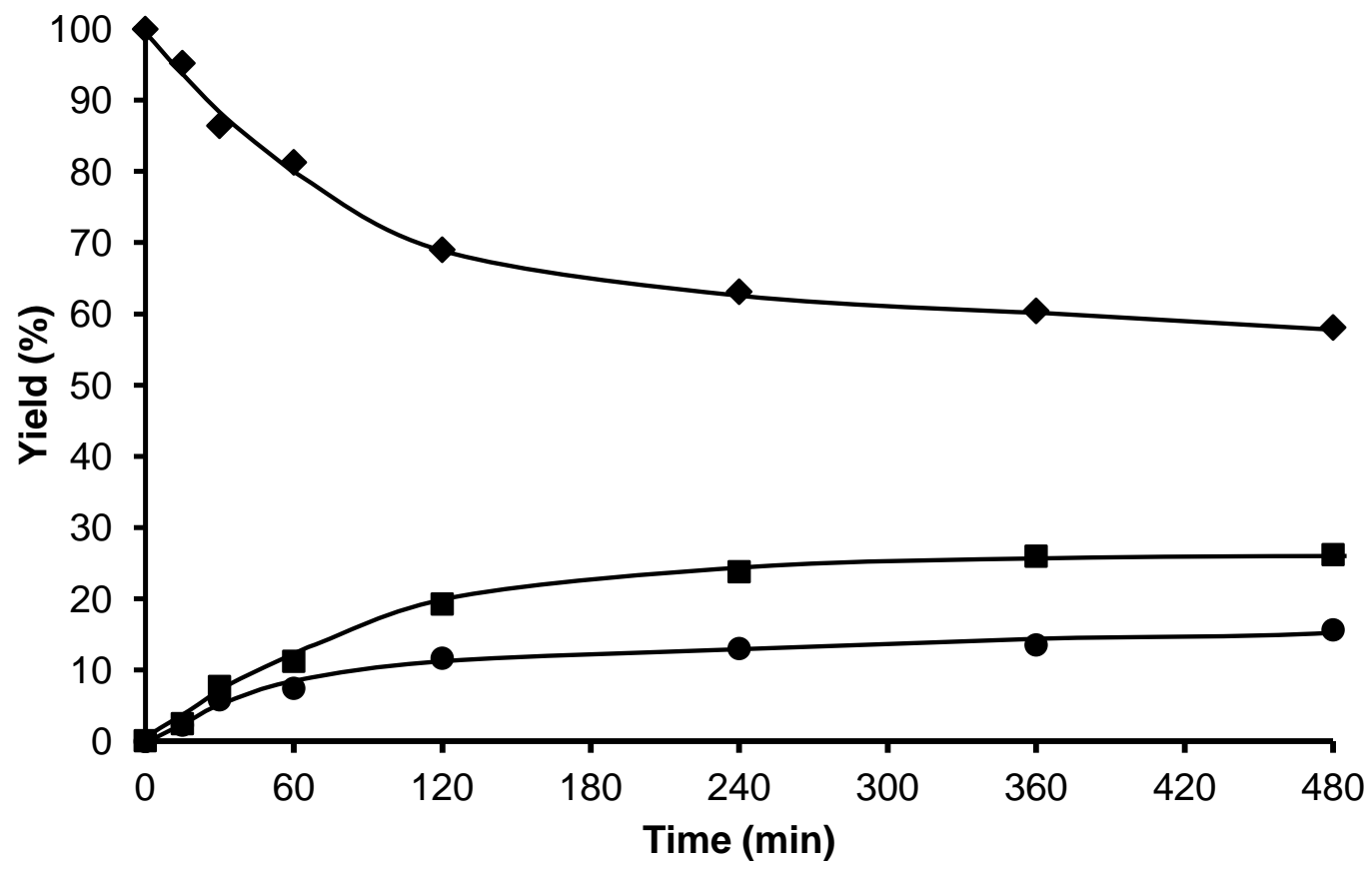

Figure 10. Kinetic curves of alkylation of toluene $(25 \mathrm{ml})$ with HMF $(0.5 \mathrm{mmol})$ in the presence of mesoporous USY-MY (25 wt\% respect HMF) at reflux temperature under nitrogen atmosphere: HMF $(\downarrow)$, 5- alkylated products: ortho, meta, para isomers ( $\square$ ) and $\operatorname{OBMF}(\bullet)$. 


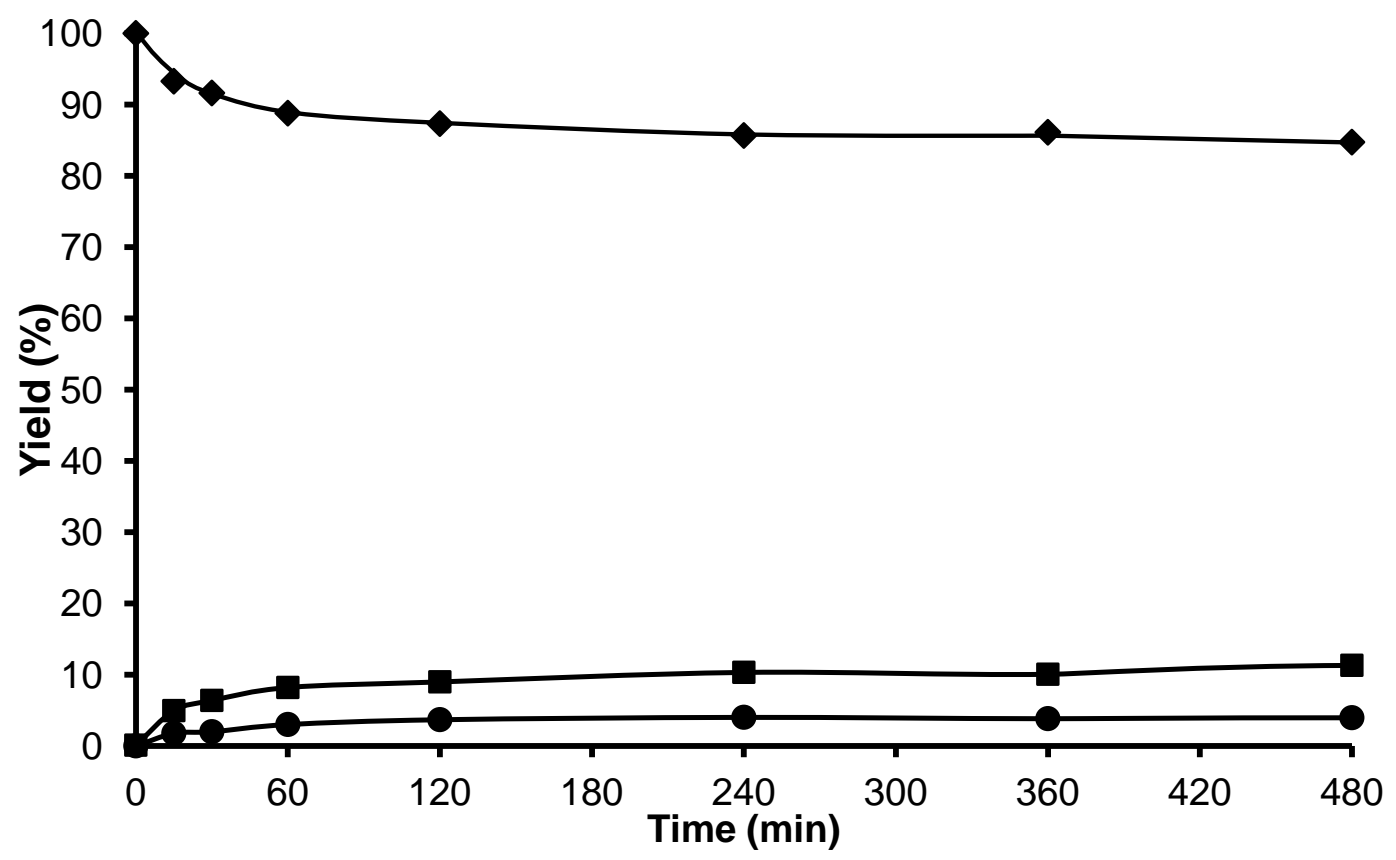

Figure 11. Kinetic curves of alkylation of toluene $(25 \mathrm{ml})$ with HMF $(0.5 \mathrm{mmol})$ in the presence of USY-HMY (25 wt\% respect HMF) at reflux temperature under nitrogen atmosphere: HMF ( $\downarrow), 5$-alkylated products: ortho, meta, para isomers ( $\square$ ) and OBMF (•). 


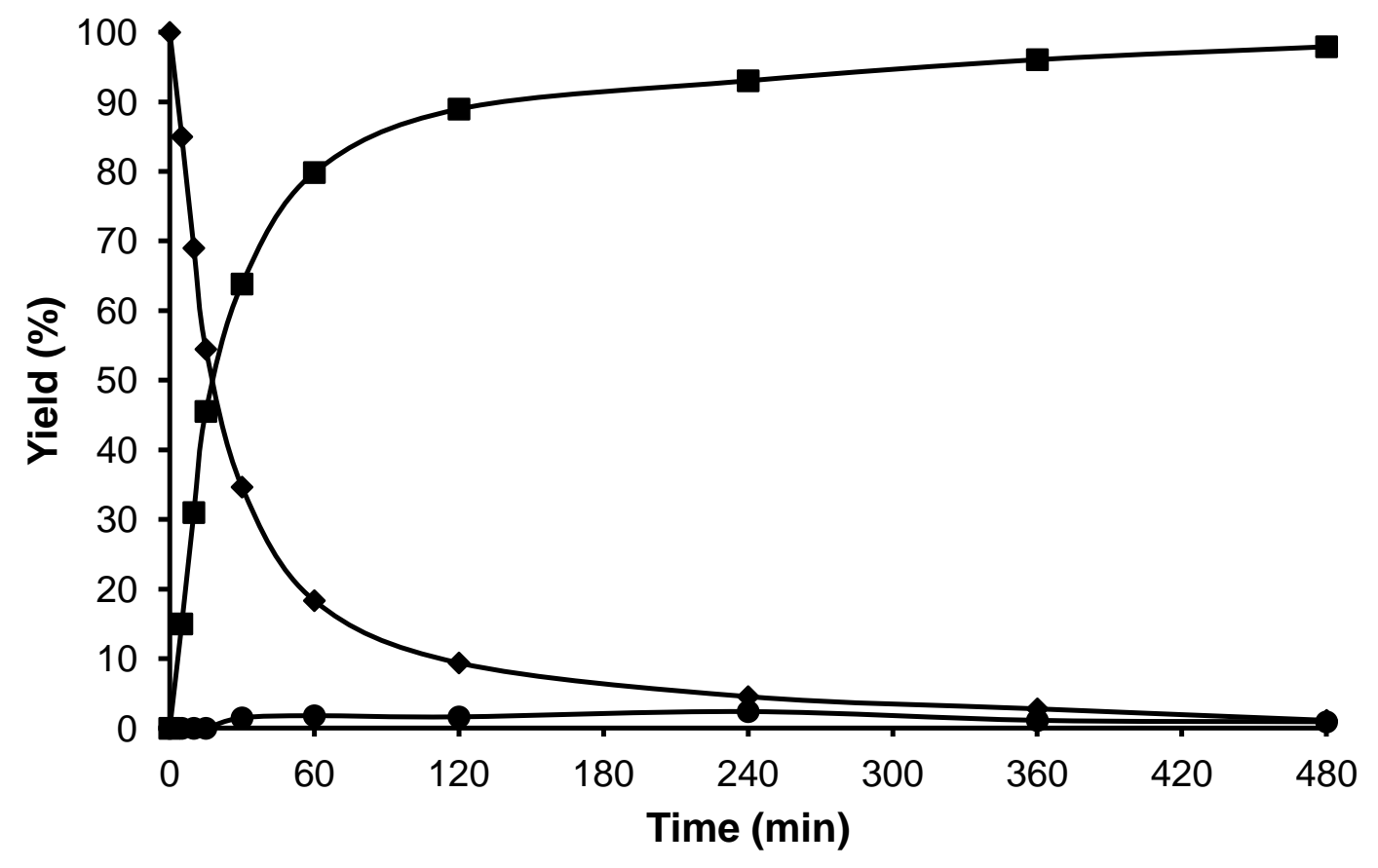

Figure 12. Kinetic curves of alkylation of toluene $(25 \mathrm{ml})$ with HMF $(0.5 \mathrm{mmol})$ in the presence of ITQ-2 (25 wt\% respect HMF) at reflux temperature and nitrogen atmosphere: HMF ( $\bullet)$, 5- alkylated products: ortho, meta, para isomers ( $\mathbf{})$ and OBMF (•) 


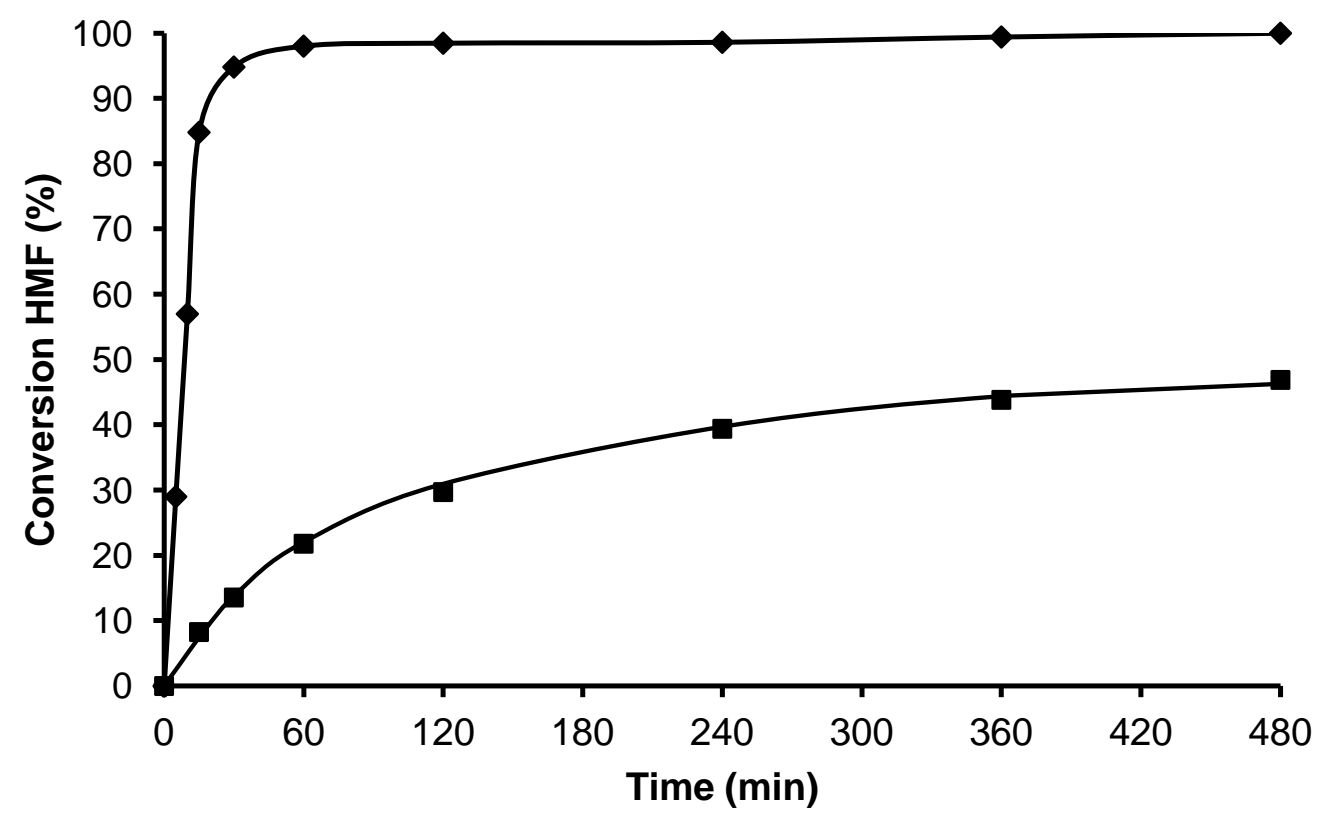

Figure 13. Conversion versus time plot for alkylation of toluene $(25 \mathrm{ml})$ with HMF $(0.5$ $\mathrm{mmol}$ ) in the presence of USY-720 $1^{\text {st }}$ cycle $(\$)$ and $2^{\text {nd }}$ cycle (after soxhlet extraction) (घ) (25 wt\% respect HMF) at reflux temperature under nitrogen atmosphere. 


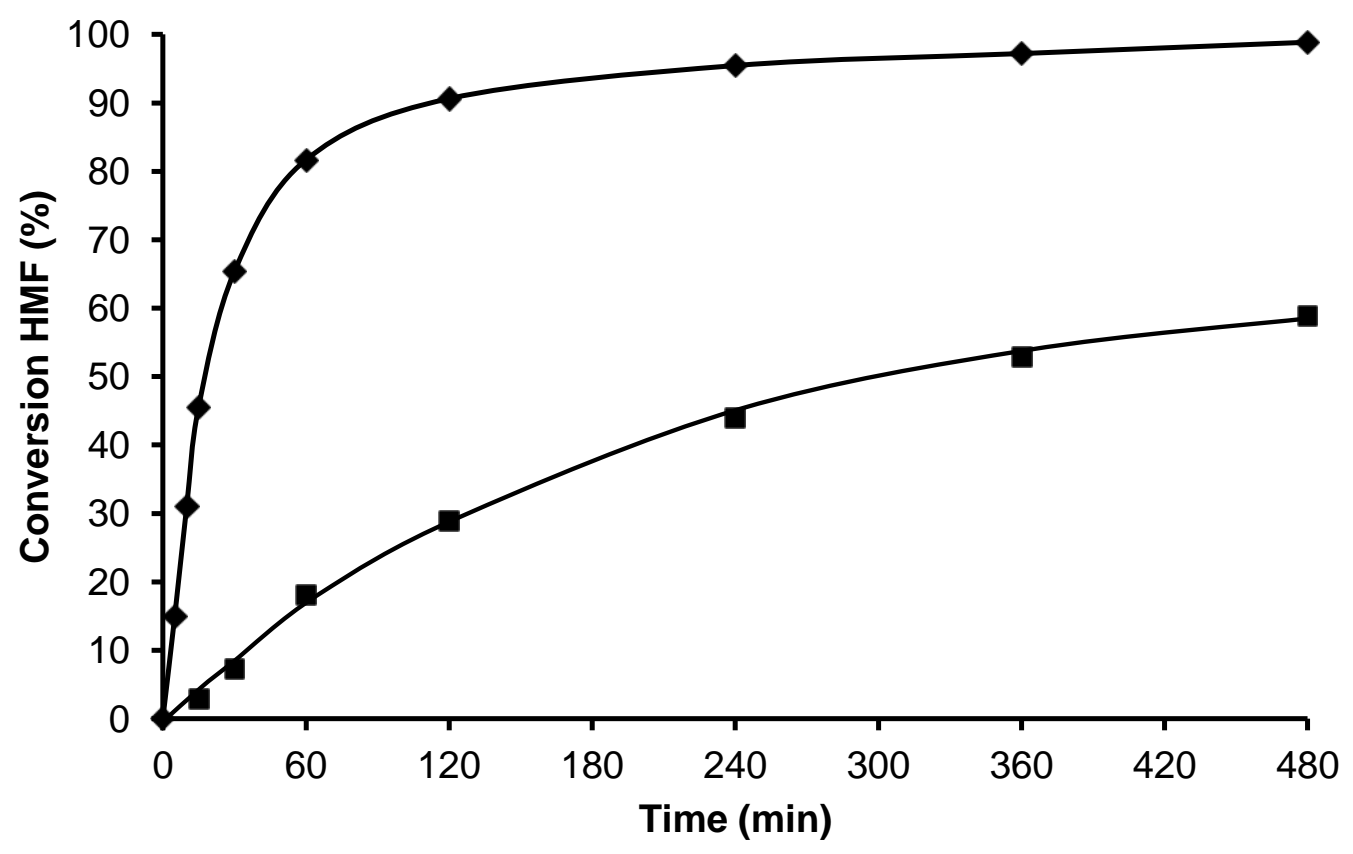

Figure 14. Conversion versus time plot for alkylation of toluene $(25 \mathrm{ml})$ with HMF $(0.5$ $\mathrm{mmol}$ ) in the presence of ITQ-2 $1^{\text {st }}$ cycle $(\diamond)$ and $2^{\text {nd }}$ cycle (after soxhlet extraction) ( $\left.\mathbf{a}\right)$ ( $25 \mathrm{wt} \%$ respect $\mathrm{HMF}$ ) at reflux temperature under nitrogen atmosphere 


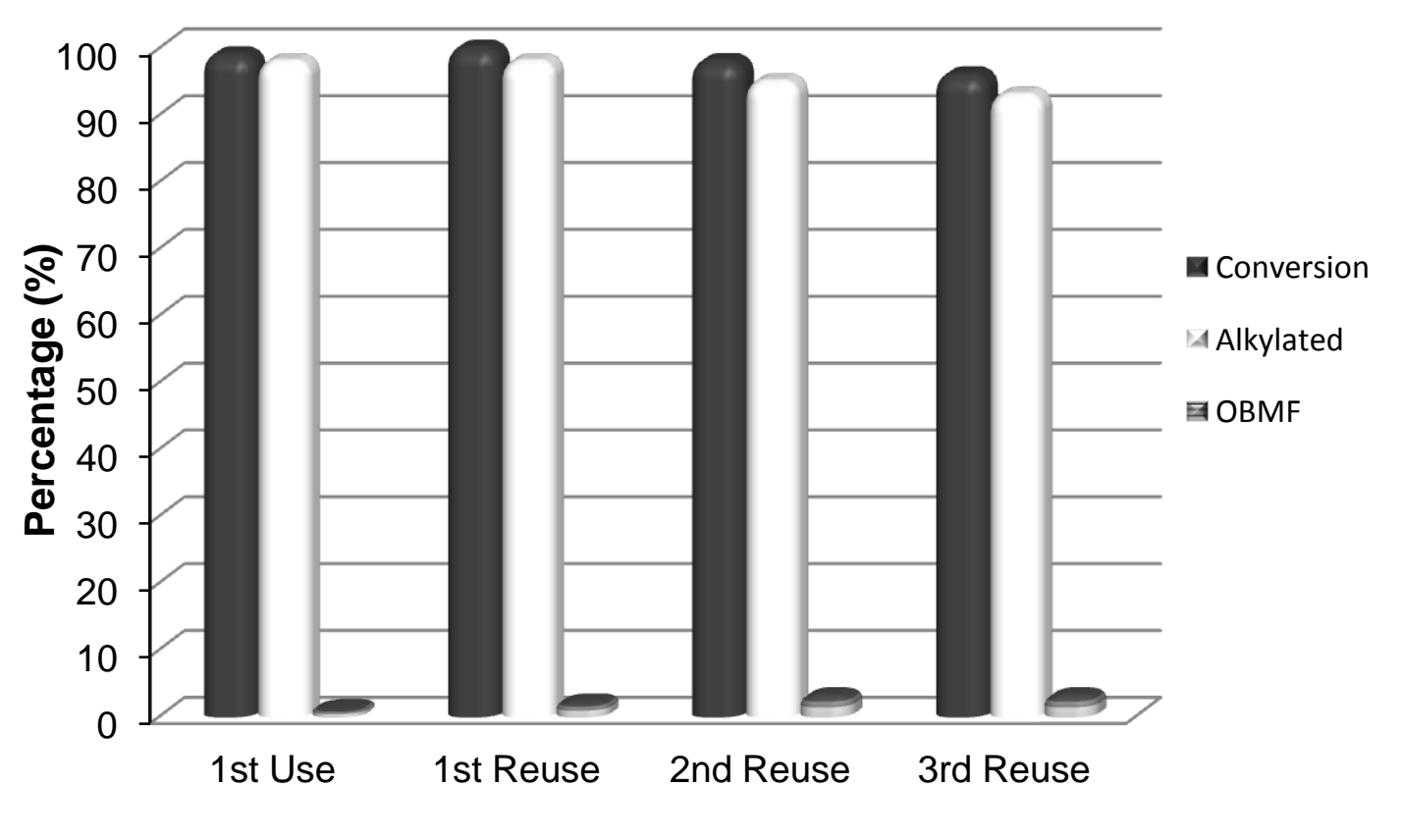

Figure 15. Reuse of the ITQ-2 zeolite. Conversion and selectivity after $8 \mathrm{~h}$ reaction time. 


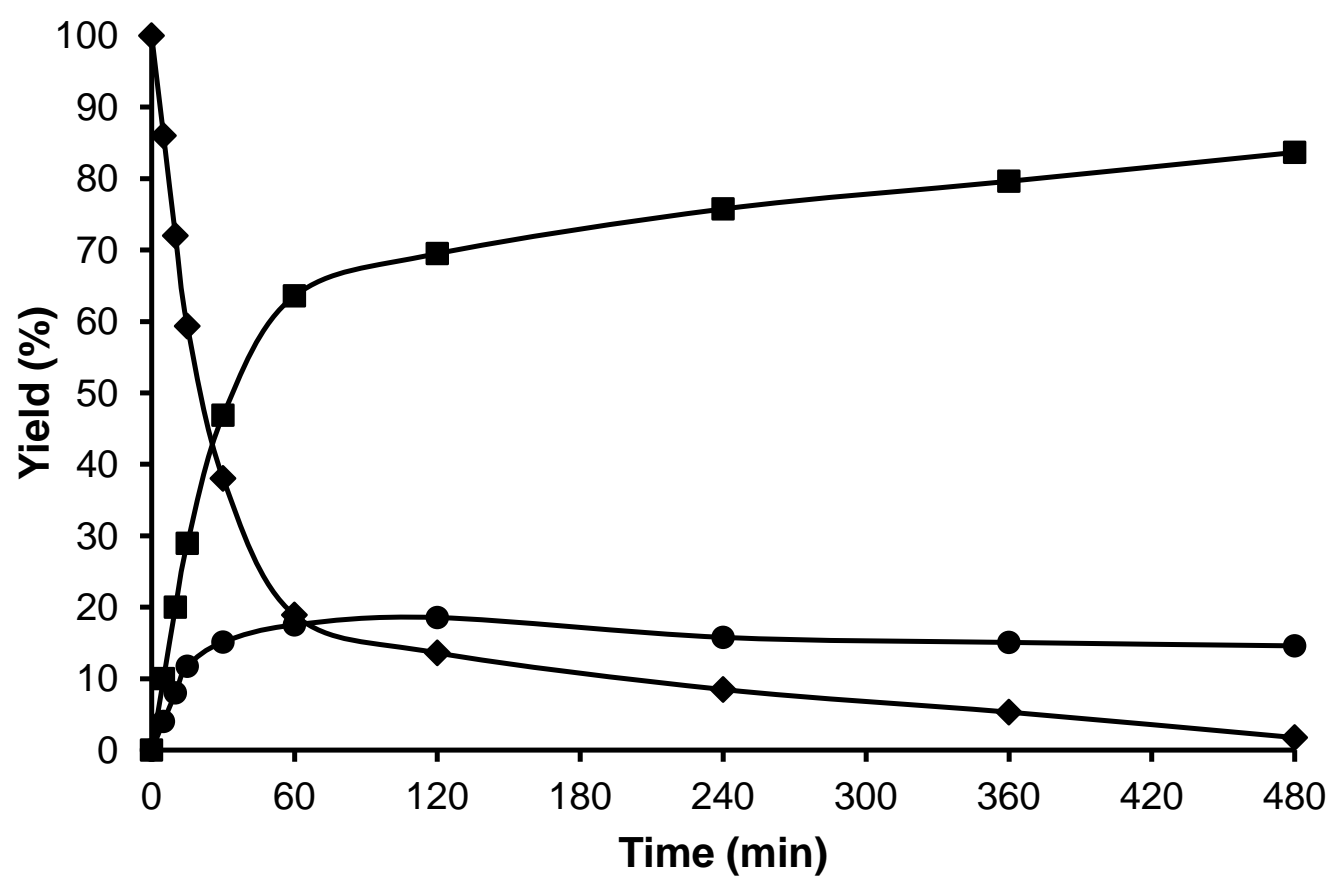

Figure 16. Kinetic curves of alkylation of toluene $(25 \mathrm{ml})$ with HMF $(0.5 \mathrm{mmol})$ in the presence of MCM-41 (25 wt\% respect HMF) at reflux temperature and nitrogen atmosphere: HMF $(\downarrow)$, 5- alkylated products: ortho, meta, para isomers ( $\mathbf{a})$ and OBMF $(\bullet)$. 


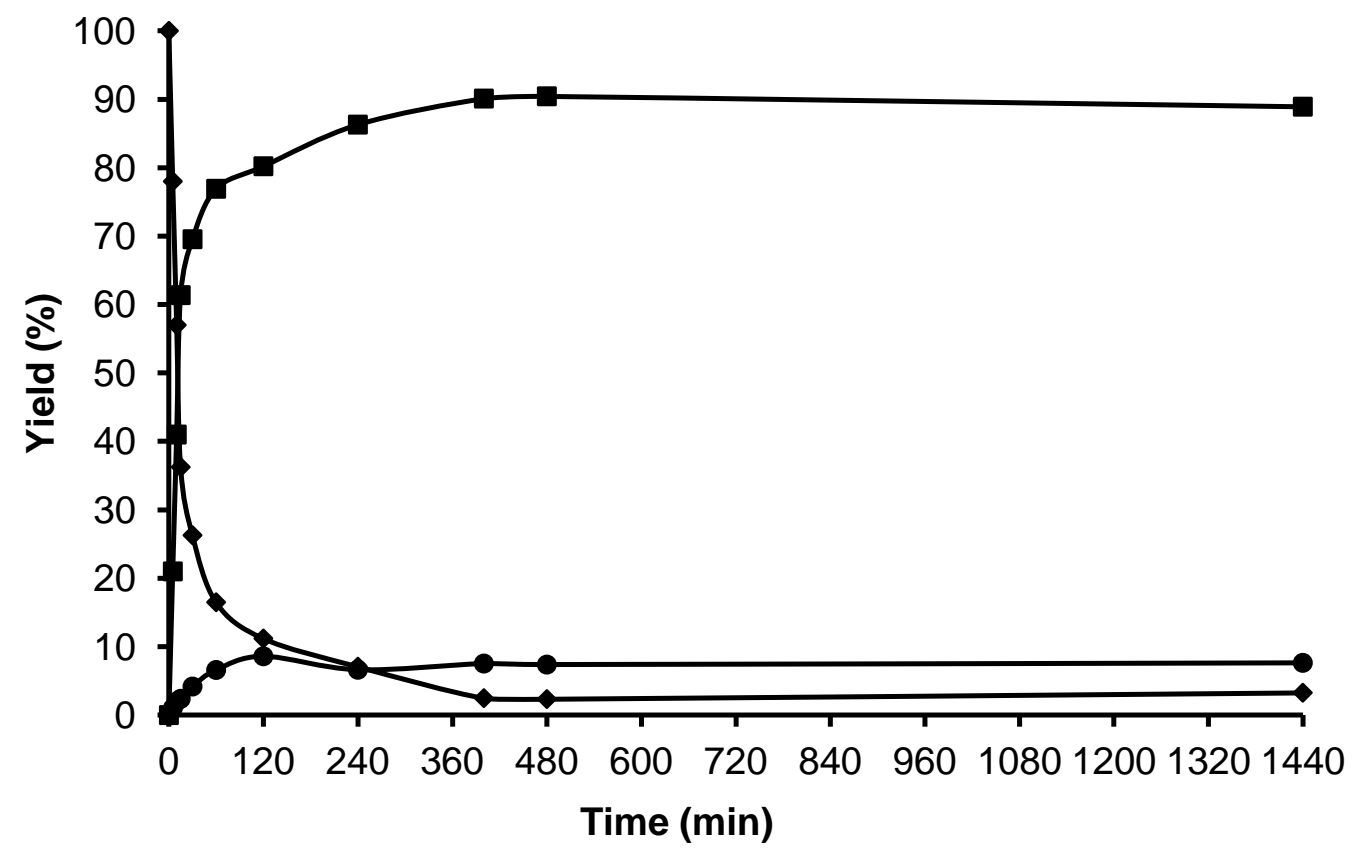

Figure 17. Kinetic curves of alkylation of a heavy reformate mixture $(5 \mathrm{ml}: 1,2,3-$ trimethylbenzenes (54 v/v\%), 3-ethyl-toluene (33.4 v/v\%), n-propylbenzene (6 v/v\%) and o-xylene $(6.6 \mathrm{v} / \mathrm{v} \%))$ with HMF $(0.5 \mathrm{mmol})$ in the presence of ITQ-2 (25 wt\% respect $\mathrm{HMF}$ ) at $150{ }^{\circ} \mathrm{C}$ and nitrogen atmosphere: $\operatorname{HMF}(\diamond), 5$ - alkylated products: ortho, meta, para isomers ( $\bullet$ ) and $\operatorname{OBMF}(\bullet)$. 


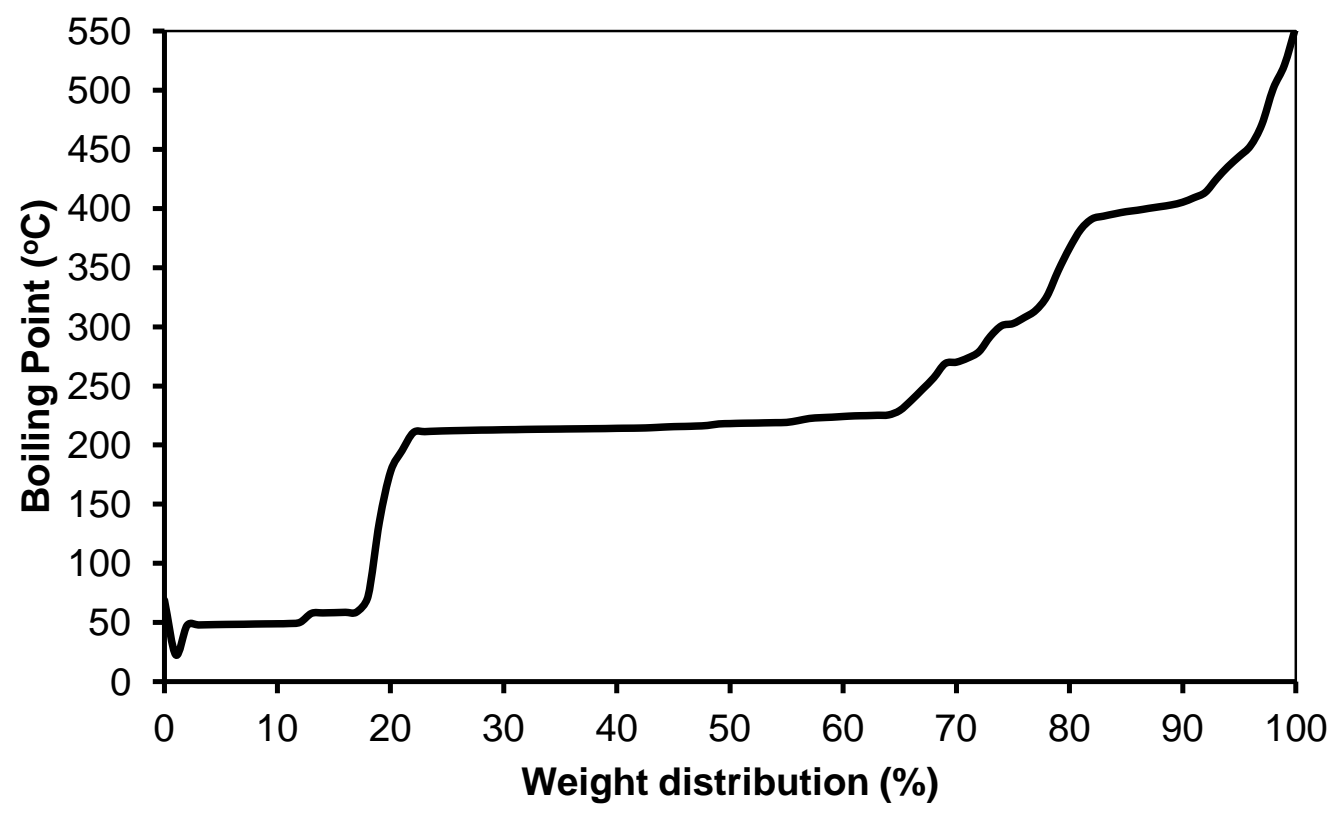

Figure 18. Simulated distillation for the product mixture obtained when 5-(o-, $\mathrm{m}$ - and p-methyl)benzylfuran-2-carbaldehyde was passed over $\mathrm{Pt} / \mathrm{C}$ and $\mathrm{Pt} / \mathrm{TiO}_{2}$ in a fixed bed reactor at a basis of a kerosene boiling point range from 200 to $300{ }^{\circ} \mathrm{C}$. 
Table 1. Results obtained in the alkylation of toluene with HMF by different acid catalysts.

\begin{tabular}{|c|c|c|c|c|c|c|c|c|}
\hline $\begin{array}{l}\text { Catalyst } \\
\text { (Si/Al) }\end{array}$ & $\begin{array}{c}r_{\text {Alk }}^{\circ} \\
10^{5} \\
\text { molmin }^{-1}\end{array}$ & $\begin{array}{c}r_{\text {OBMF }}^{\circ} \\
10^{5} \\
\text { molmin }^{-1}\end{array}$ & $\begin{array}{l}\text { Time } \\
\text { (h) }\end{array}$ & $\begin{array}{l}\text { Conv. } \\
\text { (\%) }\end{array}$ & $\begin{array}{c}\text { Yield } \\
\text { (\%) } \\
\text { OBMF }\end{array}$ & $\begin{array}{l}\text { Yield } \\
\text { (\%) Alk }\end{array}$ & $\begin{array}{l}\text { Sel. } \\
\text { (\%) } \\
\text { Alk }\end{array}$ & $\begin{array}{c}\text { Sel. } \\
\text { (\%)Alk } \\
\text { (o: p: m) }\end{array}$ \\
\hline Mordenite(10) & 0.16 & 0.14 & 8 & 20 & 9 & 11 & 55 & $27: 73: 0$ \\
\hline USY-720(12.2) & 2.56 & 0.57 & 6 & 100 & 5 & 95 & 95 & $46: 52: 2$ \\
\hline HBeta(12.5) & 0.57 & 0.14 & 6 & 69 & 15 & 54 & 78 & $24: 72: 4$ \\
\hline ITQ-2(15) & 1.54 & - & 8 & 99 & 1 & 98 & 99 & $22: 76: 2$ \\
\hline \multirow[t]{2}{*}{ MCM-41(12) } & 0.97 & 0.38 & 8 & 99 & 15 & 84 & 85 & $40: 56: 4$ \\
\hline & & & 8 & 100 & 14 & 86 & 86 & $45: 48: 7$ \\
\hline \multirow[t]{2}{*}{ PTSA $^{a}$} & 1.01 & 6.1 & & & & & & \\
\hline & & & 24 & 100 & 5 & 95 & 95 & $45: 48: 7$ \\
\hline $\begin{array}{l}\text { Reaction condi } \\
\text { temperature, } \mathrm{N}\end{array}$ & $\begin{array}{l}\text { tions: } \mathrm{HMF} \\
\text { trogen atm }\end{array}$ & $\begin{array}{l}(0.5 \mathrm{mmol} \\
\text { osphere. }^{\mathrm{a}} 1\end{array}$ & $\begin{array}{l}\text { tolue } \\
2 \mathrm{mg} \mathrm{c}\end{array}$ & $\begin{array}{l}(25 \mathrm{ml} \\
\text { TTSA wa }\end{array}$ & $\begin{array}{l}\text { atalyst } \\
\text { dded }\end{array}$ & $15.75 \mathrm{~m}$ & $(25 v$ & $\%)$, reflux \\
\hline
\end{tabular}


Table 2. Percentage of organic material remaining on the catalyst and the micropore volume of the used and Soxhlet extracted catalyst.

\begin{tabular}{ccc}
\hline Catalyst (Si/Al) & Organic material (\%) & $\mathrm{V}_{\text {micro }}$ lost (\%) \\
\hline Mordenite (10) & 10 & 17 \\
USY-720 (12.2) & 16 & 41 \\
HBeta(12.5) & 28 & 55 \\
\hline
\end{tabular}


Table 3. Acidity of USY zeolites as determined by FT-IR combined with pyridine adsorption and desorption at increasing temperatures

\begin{tabular}{|c|c|c|c|c|c|c|c|}
\hline \multirow[b]{2}{*}{ Catalyst } & \multirow{2}{*}{$\mathrm{Si} / \mathrm{Al}$} & \multicolumn{2}{|c|}{$150^{\circ} \mathrm{C}$} & \multicolumn{2}{|c|}{$250^{\circ} \mathrm{C}$} & \multicolumn{2}{|c|}{$350^{\circ} \mathrm{C}$} \\
\hline & & Brönsted & Lewis & Brönsted & Lewis & Brönsted & Lewis \\
\hline USY-300 & 2.6 & 65 & 106 & 31 & 83 & 3 & 57 \\
\hline USY-500 & 2.7 & 111 & 56 & 92 & 44 & 52 & 33 \\
\hline USY-712 & 5.6 & 58 & 25 & 49 & 19 & 31 & 14 \\
\hline USY-720 & 12.2 & 79 & 16 & 66 & 13 & 41 & 10 \\
\hline USY-760 & 27 & 24 & 11 & 21 & 10 & 6 & 7 \\
\hline USY-MY & 4.3 & 88 & 49 & 64 & 34 & 27 & 25 \\
\hline USY-HMY & 5.3 & 34 & 25 & 29 & 21 & 19 & 22 \\
\hline $\begin{array}{l}\text { Acidity } \mu \mathrm{mo} \\
\text { Ref. } 46\end{array}$ & ridin & gram catal & , calcul & ed using & tinction & coefficients & given in \\
\hline
\end{tabular}


Table 4. Physicochemical properties of USY zeolites

\begin{tabular}{|c|c|c|c|c|c|c|c|c|c|c|}
\hline \multirow{2}{*}{ Catalyst } & \multirow{2}{*}{$\begin{array}{c}\text { Unit } \\
\text { cell size } \\
(\AA)\end{array}$} & \multirow{2}{*}{$\begin{array}{l}\text { Crys. } \\
(\%)^{\mathrm{a}}\end{array}$} & \multirow{2}{*}{$\begin{array}{l}\text { Si/Al } \\
\text { (ICP) }\end{array}$} & \multirow{2}{*}{$\begin{array}{c}\mathrm{Si} / \mathrm{Al} \\
\left(\text { framew. }^{\mathrm{b}}\right.\end{array}$} & \multicolumn{3}{|c|}{ Al per unit cell } & \multirow{2}{*}{$\begin{array}{c}\text { BET } \\
\left(m^{2} g^{-1}\right)\end{array}$} & \multirow{2}{*}{$\begin{array}{c}\mathrm{V}_{\text {micro }}{ }^{\mathrm{c}} \\
\left(\mathrm{cm}^{3} \mathrm{~g}^{-1}\right)\end{array}$} & \multirow{2}{*}{$\begin{array}{c}V_{\text {meso }} \\
\left(\mathrm{cm}^{3} \mathrm{~g}^{-1}\right)\end{array}$} \\
\hline & & & & & Total & FAL & EFAL & & & \\
\hline USY-500 & 24.56 & 100 & 2.7 & 3.5 & 51.9 & 42.5 & 9.4 & 609 & 0.27 & 0.07 \\
\hline USY-712 & 24.36 & 100 & 5.6 & 12.4 & 29 & 14.3 & 15 & 593 & 0.25 & 0.13 \\
\hline USY-720 & 24.32 & 99 & 12.2 & 18.6 & 14.5 & 9.8 & 4.7 & 603 & 0.27 & 0.13 \\
\hline USY-760 & 24.26 & 36 & 27 & 63 & 6.9 & 3 & 3.9 & 509 & 0.15 & 0.20 \\
\hline
\end{tabular}


Table 5. Catalytic activity of USY zeolites in the alkylation of toluene with HMF

\begin{tabular}{|c|c|c|c|c|c|c|}
\hline Catalyst & $\begin{array}{c}\text { Si/AI(UCS) } \\
\text { FAL }\end{array}$ & Si/AI (ICP) & $\begin{array}{c}r_{\text {Alk }}^{\circ} 10^{3} \\
\left(\text { molmin }^{-1} g^{-1}\right)\end{array}$ & $\begin{array}{c}\text { Conv. }^{a} \\
\text { HMF } \\
(\%)\end{array}$ & Yield Alk(\%) & $\begin{array}{c}\text { Select. } \\
\text { (\%) }\end{array}$ \\
\hline USY-500 & 3.5 & 2.7 & 0.1 & 15 & 9 & 60 \\
\hline USY-712 & 12.4 & 5.6 & 1.7 & 99 & 91 & 92 \\
\hline USY-720 & 18.6 & 12.2 & 2.4 & 100 & 95 & 95 \\
\hline USY-760 & 63.0 & 27.0 & 2.2 & 99 & 91 & 92 \\
\hline
\end{tabular}


Table 6. Physicochemical properties of mesoporous USY zeolites

\begin{tabular}{|c|c|c|c|c|c|c|c|c|}
\hline Sample & $\begin{array}{l}\text { UCS } \\
(\AA)\end{array}$ & $\begin{array}{l}\text { Cryst. }^{\text {a }} \\
(\%)\end{array}$ & $\begin{array}{l}\text { Si/Al } \\
\text { (ICP) }\end{array}$ & $\begin{array}{l}\text { Si/AI(UCS) } \\
\text { FAL }^{\text {b }}\end{array}$ & $\% \mathrm{Na}_{2} \mathrm{O}$ & $\begin{array}{l}\text { BET } \\
\left(\mathrm{m}^{2} \mathrm{~g}^{-1}\right)\end{array}$ & $\begin{array}{l}\mathrm{V}_{\text {micro }}^{\mathrm{c}} \\
\left(\mathrm{cm}^{3} \mathrm{~g}^{-1}\right)\end{array}$ & $\left.\begin{array}{c}\mathrm{V}_{\text {meso }} \\
\left(\mathrm{cm}^{3} \mathrm{~g}\right. \\
1\end{array}\right)$ \\
\hline USY-300 & 24.64 & 100 & 2.6 & 2.7 & 2.8 & 925 & 0.30 & 0.04 \\
\hline USY-MY & 24.60 & 58 & 4.3 & 3.7 & 1.4 & 617 & 0.16 & 0.22 \\
\hline USY-HMY & 24.47 & 28 & 5.3 & 6.2 & $<0.1$ & 449 & 0.09 & 0.24 \\
\hline \multicolumn{9}{|c|}{$\begin{array}{l}\text { a }{ }^{\text {Referred to NaY CBV100. }}{ }^{\text {b }} \text { Determined by means of Breck-Flanigen }{ }^{47} \text { or Fichtner- } \\
\text { Schmittler }{ }^{48} \text { equations for zeolites with Si/Al ratios below and above } 3 \text {, respectively. }{ }^{c} \\
\text { Calculated from } t \text {-plot. }{ }^{d} \text { Calculated from BJH correlation. }\end{array}$} \\
\hline
\end{tabular}


Table 7. Influence of the Toluene/HMF molar ratio

\begin{tabular}{|c|c|c|c|c|c|c|}
\hline $\begin{array}{l}\text { Toluene/HMF } \\
\text { (mol/mol) }\end{array}$ & Tol(ml) & $\mathrm{T}\left({ }^{\circ} \mathrm{C}\right)$ & Time(h) & Yield(\%) alk. & $\begin{array}{c}\text { Yield(\%) } \\
\text { OBMF }\end{array}$ & $\begin{array}{c}\text { Selectivity } \\
\text { (\%) }\end{array}$ \\
\hline \multirow[b]{2}{*}{47} & \multirow[b]{2}{*}{2.5} & \multirow[b]{2}{*}{115} & 2 & 61 & 29 & 66 \\
\hline & & & 8 & 68 & 28 & 69 \\
\hline \multirow[b]{2}{*}{47} & \multirow[b]{2}{*}{2.5} & \multirow[b]{2}{*}{150} & 2 & 70 & 22 & 76 \\
\hline & & & 8 & 83 & 14 & 85 \\
\hline \multirow{2}{*}{47} & \multirow{2}{*}{2.5} & \multirow{2}{*}{170} & 2 & 79 & 13 & 86 \\
\hline & & & 8 & 90 & 10 & 90 \\
\hline \multirow{2}{*}{94} & \multirow{2}{*}{5} & \multirow{2}{*}{115} & 2 & 70 & 21 & 77 \\
\hline & & & 8 & 83 & 17 & 83 \\
\hline \multirow{2}{*}{$94^{a}$} & \multirow{2}{*}{5} & \multirow{2}{*}{115} & 2 & 79 & 18 & 81 \\
\hline & & & 8 & 87 & 13 & 87 \\
\hline \multirow{2}{*}{$94^{b}$} & \multirow{2}{*}{5} & \multirow{2}{*}{115} & 2 & 85 & 15 & 85 \\
\hline & & & 8 & 96 & 4 & 96 \\
\hline \multirow{2}{*}{94} & \multirow{2}{*}{5} & \multirow{2}{*}{150} & 2 & 85 & 11 & 89 \\
\hline & & & 8 & 96 & 4 & 96 \\
\hline \multirow[b]{2}{*}{189} & \multirow[b]{2}{*}{10} & \multirow{2}{*}{115} & 2 & 74 & 14 & 84 \\
\hline & & & 8 & 80 & 15 & 82 \\
\hline \multirow{2}{*}{472} & \multirow{2}{*}{25} & \multirow{2}{*}{115} & 2 & 89 & 2 & 98 \\
\hline & & & 8 & 98 & 1 & 99 \\
\hline
\end{tabular}

Reaction conditions: HMF (0.5 mmol), ITQ-2(15) (15.75 mg, 25 wt\%), $115{ }^{\circ} \mathrm{C}, \mathrm{N}_{2} ;{ }^{\mathrm{a}} 30 \mathrm{wt} \%$ ITQ-2 (15) respect HMF; ${ }^{b} 50$ wt\% ITQ-2 (15) respect HMF. 
Table 8. Alkylation of different aromatic hydrocarbons with HMF using ITQ-2(15) zeolite

\begin{tabular}{lcccc}
\hline Aromatic & HMF & $\begin{array}{c}\text { Yield(\%) } \\
\text { Conv(\%) }\end{array}$ & $\begin{array}{c}\text { Selec. (\%) } \\
\text { alkylated }\end{array}$ & \\
alkylated
\end{tabular}

a Reaction conditions: HMF $(0.5 \mathrm{mmol})$, aromatic hydrocarbon $25 \mathrm{ml}$, ITQ-2(15) (25wt\%), $115{ }^{\circ} \mathrm{C}$. 
Table 9. Composition of the organic phase of alkylated products after hydrodeoxygenation process

\begin{tabular}{|c|c|c|}
\hline \multicolumn{2}{|l|}{ Organic compounds } & $\begin{array}{r}\text { Percentages } \\
(\mathrm{wt} \%)\end{array}$ \\
\hline \multirow[t]{9}{*}{ Saturated: } & & 77.49 \\
\hline & Naphthenes $C_{13}$ & 37.58 \\
\hline & Naphthenes $C_{12}$ & 0.76 \\
\hline & Polynaphthenes & 10.44 \\
\hline & n-hexane & 2.48 \\
\hline & Naphthene $C_{7}$ & 13.92 \\
\hline & Others saturates & \\
\hline & $\left(\mathrm{C}_{9} \mathrm{H}_{18}, \mathrm{C}_{11} \mathrm{H}_{22}, \mathrm{C}_{13} \mathrm{H}_{28},>\mathrm{C}_{14}\right)$ & \\
\hline & & 12.30 \\
\hline \multirow[t]{6}{*}{ mono-aromatics: } & & 16.82 \\
\hline & Toluene & 6.31 \\
\hline & Mono-aromatics $C_{13}$ & 8.83 \\
\hline & Mono-aromatics $C_{12}$ & 0.26 \\
\hline & Others aromatics $\left(C_{8}-C_{11}\right.$ & \\
\hline & $\left.C_{14}-C_{18}\right)$ & 2.61 \\
\hline di-aromatics & & 2.70 \\
\hline tri-aromatics & & 1.59 \\
\hline \multirow[t]{2}{*}{ Polars } & & 0.21 \\
\hline & & 100.00 \\
\hline
\end{tabular}


Table 10. Results of the simulated distillation

\begin{tabular}{ccc}
\hline $\mathrm{T}\left({ }^{\circ} \mathrm{C}\right)$ & Fraction & Percentage (wt\%) \\
\hline 150.8 & Ligh Gasoline & 19.25 \\
216.1 & Heavy Gasoline & 27.84 \\
359 & kerosene & 32.54 \\
482 & HCO (gasoil) & 17.78 \\
1000 & slurry & 2.63 \\
\hline
\end{tabular}


Table 11. Main characteristics of the different catalysts

\begin{tabular}{|c|c|c|c|c|c|c|c|c|}
\hline \multirow{2}{*}{ Catalyst } & \multirow{2}{*}{$\begin{array}{c}\text { BET } \\
\left(\mathrm{m}^{2} / \mathrm{g}\right)\end{array}$} & \multirow{2}{*}{$\begin{array}{c}\text { Pore } \\
\text { vol. } \\
\left(\mathrm{cm}^{3} / \mathrm{g}\right)^{\mathrm{a}}\end{array}$} & \multicolumn{2}{|c|}{$150^{\circ} \mathrm{C}$} & \multicolumn{2}{|c|}{$250^{\circ} \mathrm{C}$} & \multicolumn{2}{|c|}{$350^{\circ} \mathrm{C}$} \\
\hline & & & Brönsted & Lewis & Brönsted & Lewis & Brönsted & Lewis \\
\hline HBeta(12.5) & 602 & 0.36 & 65 & 69 & 58 & 56 & 25 & 29 \\
\hline USY-720(12.2) & 780 & 0.49 & 79 & 16 & 66 & 13 & 41 & 10 \\
\hline ITQ-2(15) & 643 & 0.53 & 57 & 27 & 37 & 18 & 16 & 13 \\
\hline MCM-41(15) & 1100 & 0.94 & 19 & 62 & 5 & 46 & 4 & 34 \\
\hline Mord.(10) & 550 & 0.40 & 67 & 25 & 54 & 25 & 29 & 28 \\
\hline $\begin{array}{l}\text { Acidity } \mu \mathrm{mol} \\
\text { coefficients give }\end{array}$ & $\begin{array}{l}\text { idine } \\
\text { in Ref }\end{array}$ & $\begin{array}{l}\text { gram ca } \\
46 .\end{array}$ & at & nt & erature & $\mathrm{lc}$ & d using & ction \\
\hline
\end{tabular}

